San Jose State University

SJSU ScholarWorks

Master's Theses

Master's Theses and Graduate Research

Fall 2019

\title{
Comparing Levels Of Environmental Literacy Between Stars- and Non-Stars-Rated Universities
}

AnaLisa Kathleen Campos

San Jose State University

Follow this and additional works at: https://scholarworks.sjsu.edu/etd_theses

\section{Recommended Citation}

Campos, AnaLisa Kathleen, "Comparing Levels Of Environmental Literacy Between Stars- and Non-StarsRated Universities" (2019). Master's Theses. 5058.

DOI: https://doi.org/10.31979/etd.9agy-6fmq

https://scholarworks.sjsu.edu/etd_theses/5058

This Thesis is brought to you for free and open access by the Master's Theses and Graduate Research at SJSU ScholarWorks. It has been accepted for inclusion in Master's Theses by an authorized administrator of SJSU ScholarWorks. For more information, please contact scholarworks@sjsu.edu. 


\title{
COMPARING LEVELS OF ENVIRONMENTAL LITERACY BETWEEN STARS-
} AND NON-STARS-RATED UNIVERSITIES

\author{
A Thesis \\ Presented to \\ The Faculty of the Department of Environmental Studies \\ San Jose State University
}

\author{
In Partial Fulfillment \\ of the Requirements for the Degree \\ Master of Science
}

by

AnaLisa K. Campos

December 2019 
(C) 2019

AnaLisa K. Campos

ALL RIGHTS RESERVED 
The Designated Thesis Committee Approves the Thesis Titled

COMPARING LEVELS OF ENVIRONMENTAL LITERACY BETWEEN STARSAND NON-STARS-RATED UNIVERSITIES

by

AnaLisa K. Campos

APPROVED FOR THE DEPARTMENT OF ENVIRONMENTAL STUDIES

SAN JOSÉ STATE UNIVERSITY

December 2019

Dr. Carolina Prado

Dr. Will Russell

Dr. Jason Douglas
Department of Environmental Studies

Department of Environmental Studies

Department of Health Sciences 


\title{
ABSTRACT \\ COMPARING LEVELS OF ENVIRONMENTAL LITERACY BETWEEN STARS- AND NON-STARS-RATED UNIVERSITIES
}

\author{
by AnaLisa K. Campos
}

The Sustainability Tracking, Assessment, and Rating System (STARS) is a program that measures university sustainability levels. STARS ranks university campuses based on the number of points received from individual specifications such as green buildings, access to mass transit, number of environmental courses, and more. Therefore, the rank a school receives translates directly to its level of sustainability as an institution. Currently, it is unknown if there is a relationship between a campus's STARS-rating and individual students' environmental literacy (EL). The purpose of this project was to analyze the impacts of university's sustainable features on student EL. Surveys were administered to 1,988 students attending both STARS-ranked universities and non-STARS-ranked universities. The survey measured the three components of student EL: environmental attitude (EA), environmental behavior (EB), and knowledge (EK) about the environment. Results indicated that students shared similar EL scores regardless of their campus STARS rank or lack of STARS participation. Some differences between EL levels were found among certain demographics. Gender significantly influenced EB, while class standing significantly influenced EK. Those who preferred not to choose a gender (PNA) scored significantly higher than males and females in EB. EK scores between grade levels showed a significant difference between grade levels and increased as grade level increased. To ensure an environmental literate student population, universities should incorporate environmental concepts into more courses within all majors/departments. 


\section{AKNOWLEDGMENTS}

First, I'd like to thank my thesis committee: My chair, Dr. Carolina Prado for jumping into my committee with excitement and meeting with me weekly via webcam while I worked 400 miles away. Dr. Will Russell, thank you for your continued support from the beginning of my journey as a graduate student. Thank you, Dr. Jason Douglas for providing invaluable advice and accountability in the beginning stages of my thesis. All your dedication and guidance mean more to me than you can know. I also owe a big thanks to each faculty and staff member from each university that sent my survey out to their students! Without ever meeting face-to-face, many professors trusted in my project and shared my survey with their students. This kind of educational support was extremely encouraging; as it will forever serve as an example of the pay-it-forward attitude I wish to pass on to those after me!

Next, I want to thank my incredible family. To my mom, Cathy Campos: none of this could have happened without you. I am incredibly fortunate to be your daughter. Not only did you support and encourage me throughout my entire graduate school endeavor, but you also demonstrated so much patience every step of the way. Thank you for always steering me in the right direction and pushing me to persevere through the hardest of moments.

To my sister, Adriana: Thank you for proofreading as much as you can and for always checking up on me to hear about my progress! Your suggestions \& knowledge are forever unparalleled! I do not deserve the support system that you granted me, but I'll take it! 
To my fiancé, Michael: Thank you for your (also unparalleled) wisdom and advice! I will never know how I became so lucky to have you in my corner, supporting me every step of the way. Thank you for all your help!

This project is dedicated to my father, David Campos (1949 - 2016), who would have been so proud to see this finished product. Thank you for your unwavering love and guidance every second of my life. You always believed I could accomplish anything I put my mind to. I can still hear you cheering for me. Thank you for everything, dad. I love you! 


\section{TABLE OF CONTENTS}

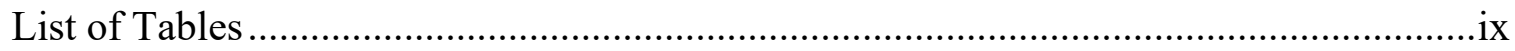

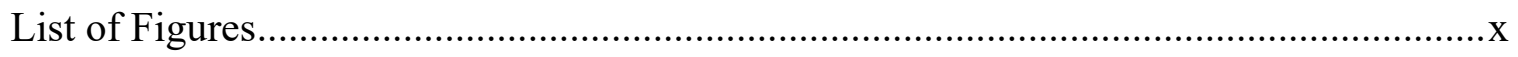

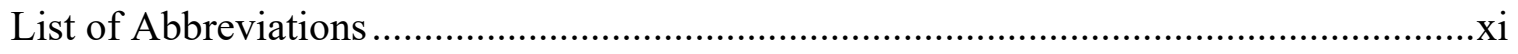

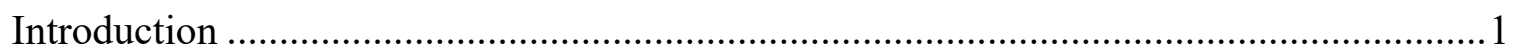

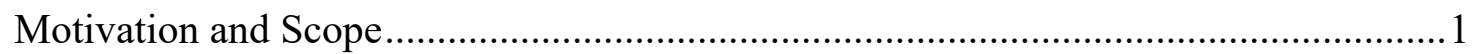

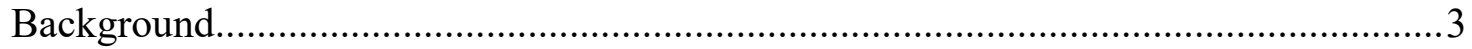

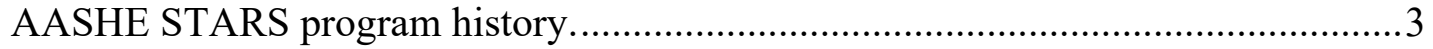

STARS criteria \& components. ..................................................................... 3

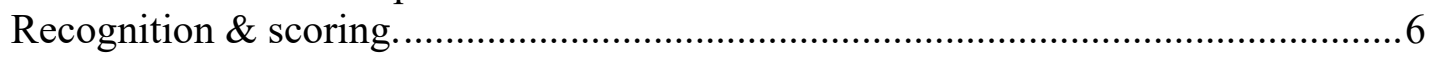

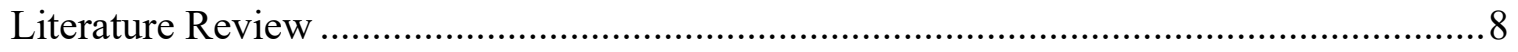

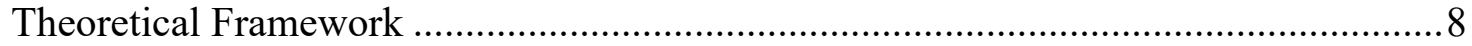

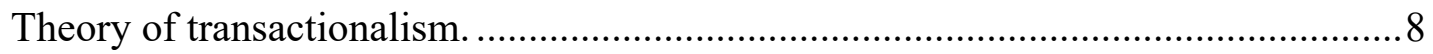

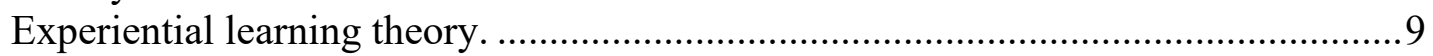

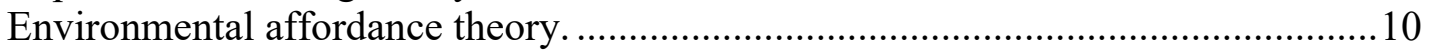

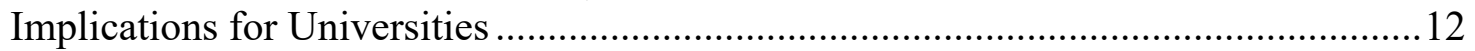

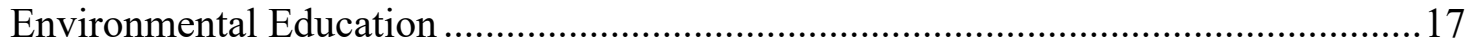

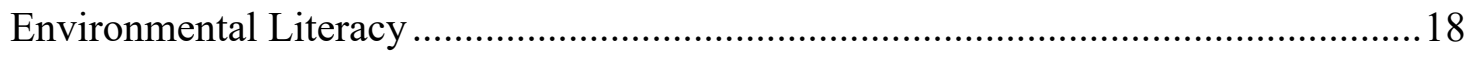

Problem Statement, Research Objectives, and Questions .........................................28

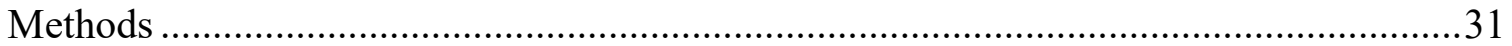

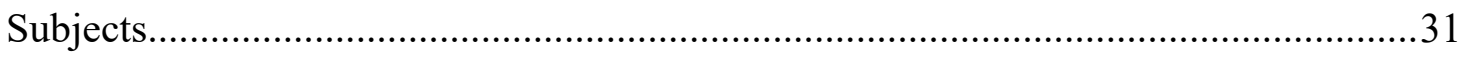

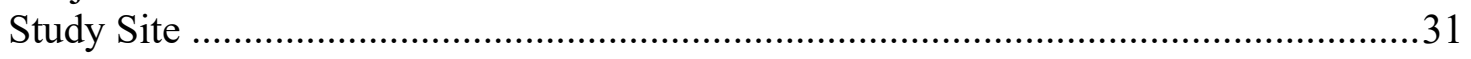

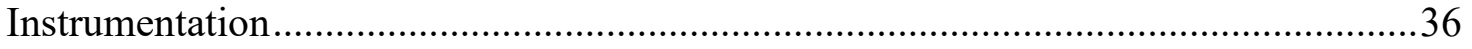

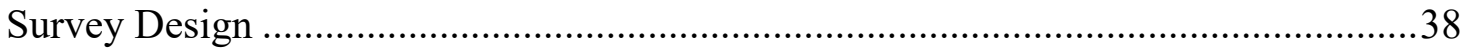

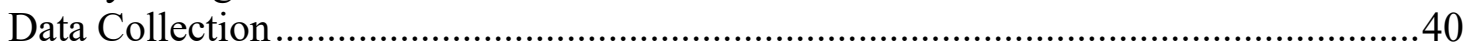

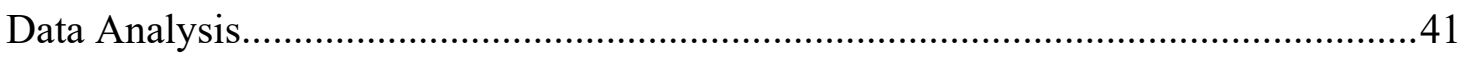

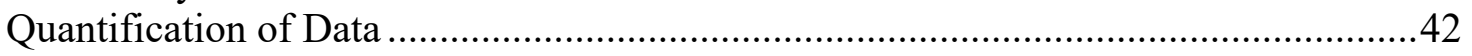

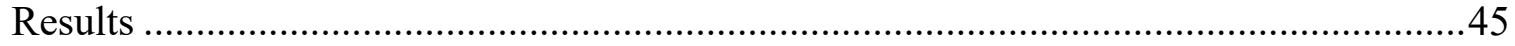

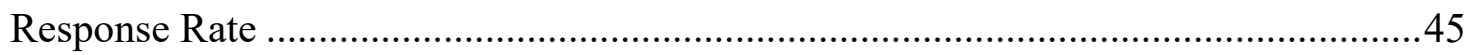

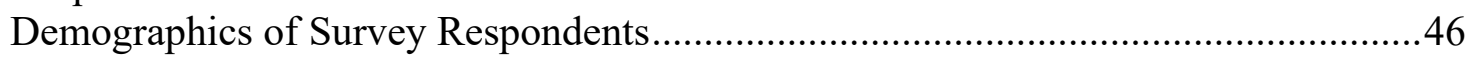

Central Tendency and Frequency Distribution of EL Scores....................................48

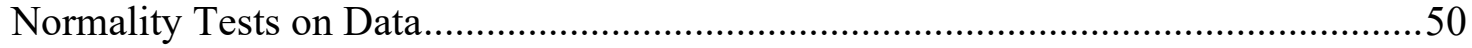

Environmental Literacy between Non-STARS and STARS-Rated Schools ................51

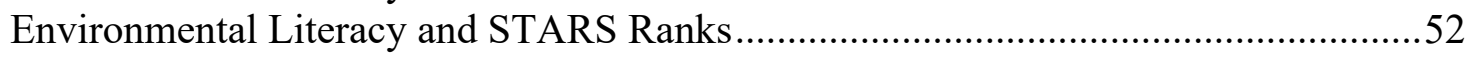


Relationship Between Environmental Literacy Components.

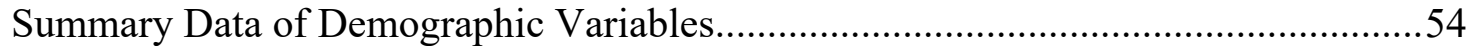

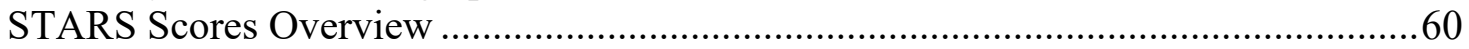

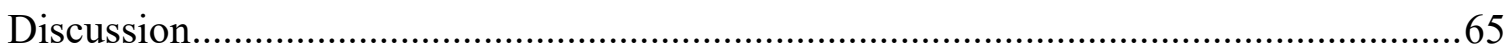

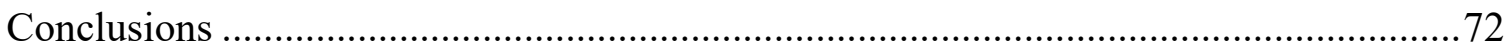

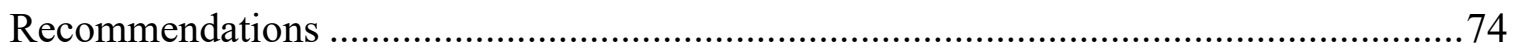

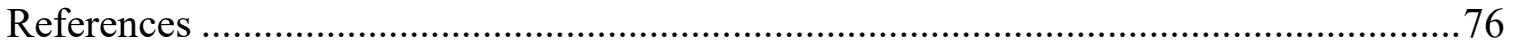

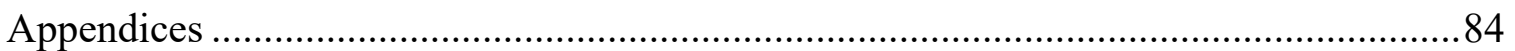

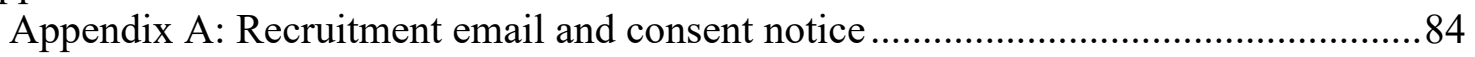

Appendix B: Environmental Literacy Survey Instrument ...................................... 85 


\section{LIST OF TABLES}

Table 1. Minimum Points Required for Each STARS-Rating ....................................... 7

Table 2. List of all STARS-Rated Universities in California as of February 2018..........33

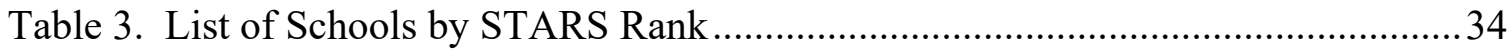

Table 4. Demographic Characteristics of Survey Respondents From Each STARS Category and Non-STARS-Rated Schools............................................... 47

Table 5. Frequency Statistics for Environmental Literacy .............................................48

Table 6. Normality Test Results on Environmental Score Data ..................................50

Table 7. Results Comparing EL Between STARS-Rated Schools and Non-STARS ......51

Table 8. Relationship Between STARS Ranks and Environmental Literacy ..................52

Table 9. Correlation Between Environmental Literacy Components.............................54

Table 10. Correlation Between Demographics ......................................................55

Table 11. Demographic Variables on Environmental Literacy .....................................56

Table 12. Correlation Between STARS Ranks ...........................................................57

Table 13. Environmental Literacy Component Scores Results Based on Gender ..........58

Table 14. Environmental Literacy Component Scores Results Based on Class

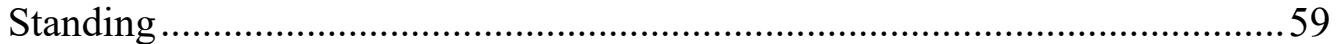

Table 15. Environmental Knowledge Scores on Class Standing and STARS Ranks ......60 


\section{LIST OF FIGURES}

Figure 1. Three dimensions of EL: attitude, behavior, and knowledge ........................ 21

Figure 2. Geographical locations and photos of the universities across California ..........35

Figure 3. Frequency distributions of environmental literacy scores ........................... 49

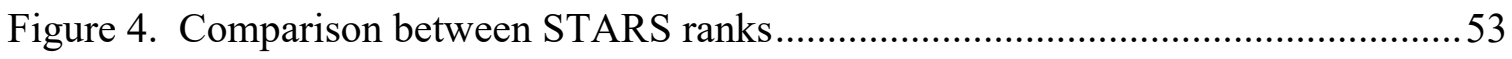

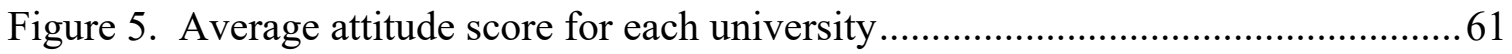

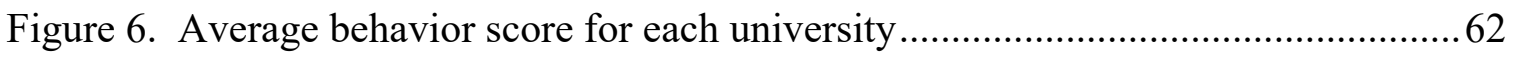

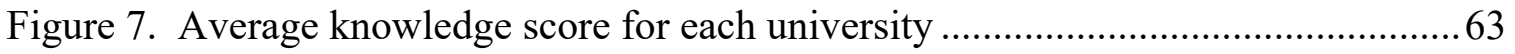

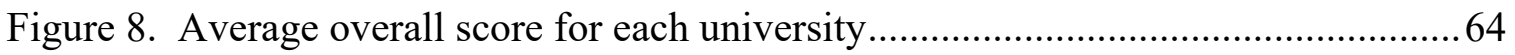




\section{LIST OF ABBREVIATIONS}

AASHE - Association for the Advancement of Sustainability in Higher Education EFS West - Education for Sustainability Western Network

EL - Environmental Literacy

EPA - Environmental Protection Agency

HEASC - Higher Education Associations Sustainability Consortium

LEED - Leadership in Energy and Environmental Design

STARS - Sustainability Tracking \& Assessment Reporting System

WES - Wisconsin Environmental Survey

WCEE - Wisconsin Center for Environmental Education

WHSSES - Wisconsin High School Student Environmental Survey

EA - Environmental Attitude

EB - Environmental Behavior

EK - Environmental Knowledge 


\section{Introduction}

\section{Motivation and Scope}

Universities across the world act as temporary communities for fostering curiosity and innovation among their student populace. In a four-year window of time, the habits students learn and ideas that they are exposed to can make lasting impacts on the perspectives they exhibit throughout their lives (Orr, 1994). Universities have the unique opportunity and responsibility to shape students' ecological perspectives (Alshuwaikhat \& Abubakar, 2008; Uhl \& Anderson, 2001). Universities play a crucial role in rearing students to become exemplary citizens of the global community, all the more reason for universities to be accountable for their influences on student success by being an example of mitigation to environmental issues.

For students to receive first-hand examples and techniques on proper environmental conduct, universities need to first improve their current method of operation (Pierce, 1992). When a university adopts ecological operating procedures, it saves that institution as well as the very Earth we live on from further contributing to environmental degradation (Uhl \& Anderson, 2001; Wang et al., 2013). Within recent years, many universities across the United States have made incredible strides to reduce carbon emissions, conserve water, and conserve energy. These changes were mainly fueled by pressure from governmental agencies, environmental activists groups, and sustainability movements (Alshuwaikhat \& Abubakar, 2008). For instance, in 2000, the Environmental Protection Agency (EPA) mandated colleges and universities to follow the same standards as industries by enforcing compliance with federal environmental requirements 
(Schaeffer, 2000). Universities have since complied with EPA standards by strategically planning long-term environmental campaigns by investing in zero waste treatment facilities, renewable energy plants, recycling programs, and more. Schools have also built LEED-certified buildings, created alternative transportation incentives, and have endorsed zero food waste initiatives. For example, San Jose State University offers its students and faculty a subsidized cost for unlimited transportation on Santa Clara Valley Transportation Authority (VTA) buses and light rail (SJSU, 2017). The University of Colorado has erected three LEED-certified Platinum and six LEED-certified Gold oncampus buildings (UCB, 2017). Implementing these changes not only encourages responsible practices, but the monetary benefits are also significant. For instance, Carleton University in Ottawa, Canada installed a \$20 million cogeneration facility, which uses geothermal energy to heat buildings in the wintertime (Pierce, 1992). Carleton University's renewable energy plant not only reduces greenhouse gas emissions but also saves Carleton University \$2 million a year (Pierce, 1992).

For the efforts universities have made towards producing environmentally friendly campuses, they are given the opportunity to be rated by the Association for the Advancement of Sustainability in Higher Education (AASHE). AASHE created a selfreporting tool for colleges and universities to measure their sustainability performance known as STARS. Through STARS, universities can participate to be recognized as one out of five possible ratings: Platinum, Gold, Silver, Bronze, or Reporter. Although AASHE STARS has established a proficient framework for measuring the sustainability of campus administration, management, and infrastructure, it does not reflect the EL of 
the student body. It is important to understand which characteristics of a college campus affect the EL of its students, and to what extent they make a lasting influence on their future decisions regarding sustainability. Determining which programs and management practices most positively affect rates of EL in students will help colleges choose where to focus when implementing or promoting new programs.

\section{Background}

AASHE STARS program history. In 2004, EFS West (Education for Sustainability Western Network) held the first North American Conference on Sustainability in Higher Education in Portland, Oregon (AASHE, n.d.-a). The conference was such a success that AASHE (Associations for the Advancement of Sustainability in Higher Education) was launched the next year "serving as the first professional higher education association for the campus sustainability community in North America" (AASHE, n.d.-a). In December of 2005, an organization called HEASC (Higher Education Associations Sustainability Consortium) was formed to "enhance the capacity of higher education to fulfill its unique and critical role in creating a healthy, just, and sustainable future" (AASHE, n.d.-b).

HEASC "recognized the need to create a university sustainability rating system that could address all dimensions of campus sustainability," and had AASHE develop STARS, the first higher education sustainability tracking system (Shek \& Hollister, 2017). STARS aims to establish strong and long-lasting sustainable college and university campuses by offering incentives and providing a framework to measure sustainability performance.

STARS criteria \& components. All details relating to STARS criteria and tracking functionality can be found directly on the AASHE STARS website including the 
following information on each section of the STARS report. Although AASHE STARS requires a membership subscription to create and update reports, access to completed reports is free and accessible to the public. Below is a brief overview of each required component of the STARS online tracking system. As of the most updated (2.1) version of STARS, there are six main sections: (1) Institutional Characteristics, (2) Academics, (3) Engagement, (4) Operations, (5) Planning and Administration, and (6) Innovation and Leadership. The first section, "Institutional Characteristics," offers zero points towards the overall score since this section is simply identifying basic demographics and academic information about the institution.

The Academics section distributes points for sustainability-related curriculum and research. This section asks, "How many sustainability courses are offered by the institution?" Points are awarded depending on the percentage of sustainability courses out of the total number of courses offered by the institution. The number of individual departments offering at least one sustainability-related course is also considered. The "research" portion of this section considers the number of faculty and staff who are engaged with sustainability research. This also includes the support, in terms of grants and scholarships, available to students and staff for funding projects relating to sustainability.

The third section of the report, "Engagement," is separated into two subsections: "Campus Engagement" and "Public Engagement." "Campus Engagement" includes the following questions: How is the subject of sustainability included in new student orientations? How many sustainability-related student groups or clubs does the 
institution currently have? What is the number of gardens, farms, community-supported agriculture or fishery programs, and urban agriculture projects? Does the institution have a sustainability-related website, newsletters, social media platforms, or regular coverage in the campus newspapers? Gardens and other sustainability-rated programs provide students with hands-on experience in the environmental realm of work. Kolb's (1984) experiential learning theory claims that positive experiences are capable of predicting positive lifelong actions and behaviors. Therefore, measuring "Campus Engagement" may be the impetus for discovering a connection to increased EL.

Next, "Public Engagement" awards points based on an institution's involvement with community partnerships that advance sustainability. These community partnerships are meant to go beyond environmental protection and also focus on social responsibility and economic assistance.

The "Operations" section distributes points for any sustainable tactics being used for air and climate, buildings, energy, food and dining, grounds, purchasing, transportation, waste, and water. This is the section that considers the presence of LEED buildings, waste reduction methods, and water conservation initiatives, as well as vegan/vegetarian dining options, and transportation subsidies. Is the fauna and flora around campus drought-tolerant? How is electronic waste disposed of? Are food purchases from fairtrade or local sources? These types of questions and more are covered in "Operations."

The second-to-last section within the STARS assessment is "Planning and Administration," which covers coordination, planning, diversity, affordability, investments, finances, and wellbeing. Under "coordination" and "planning," points are 
awarded for having a sustainability committee, a sustainability office, an officer or a fulltime employee for the sustainability office, and substantive accomplishments of the committee. Under "diversity" and "affordability," institutions are asked if there is a diversity and equity committee, office, or an officer tasked to advise on and implement policies, programs, and trainings related to diversity, equity, inclusion, and human rights on campus. In the "investments" and "finances" portions, points are given if the institution can prove to have a formally-established and active committee on investor responsibility (CIR) that makes recommendations to fund decision-makers on sociallyand environmentally-responsible investment opportunities across asset classes.

The sixth and final section of the STARS assessment, "Innovation and Leadership," addresses bicycle friendliness, fair trade initiatives, and any innovative policy, practice, program or outcomes implemented by the university. Bicycle friendliness encompasses any rider incentives, structures, or on-campus amenities that encourage commuting by bicycle to create a comfortable cycling environment. The idea of fair-trade initiatives stems from the desire to have campuses aware of fair-trade issues and ensure that any food or material products sold on campus support social, economic, and environmental justice and sustainability. The final section, "Innovation," grants universities the opportunity to discuss the impacts of any unique, innovative, and university-wide movements that address sustainability challenges.

Recognition \& scoring. After each university submits its STARS report, the school will receive its rank depending on its overall score. The overall score is determined by how closely the university meets the criteria to receive full or partial 
credit. Table 1 illustrates the minimum amount of required points that is required for the different STARS ranks (Bronze, Silver, Gold, and Platinum). Mentioned earlier was a fifth rank known as "Reporter" which describes an institution that participated in the program, yet for undeclared reasons, wished to keep its scores and rank status private. According to Table 1, a campus that receives 60 points for its report will receive a Silver ranking.

Table 1

Minimum Points Required for Each STARS Rating

\begin{tabular}{ll}
\hline STARS Rating & Minimum Points Required \\
\hline Bronze & 25 \\
Silver & 45 \\
Gold & 65 \\
Platinum & 85 \\
\hline
\end{tabular}

Note. Adapted from AASHE STARS technical manual version 2.1

Each subsection within the STARS report grants a certain number of points depending on the percentage of how closely the institution meets the criteria outlined within each section. Although the reporter does not grade or score its own report, the reporter can comfortably predict the score of the report based on the criteria that were provided. For example, a total of 14 points are available within the Academic Courses category. Part 1 of Academic Courses allocates 8 points, while Part 2 allocates 4 points. The criteria for Part 1 to receive the full 8 points is that 20 percent of all courses offered by the university need to either be focused on sustainability or be related to sustainability. If an institution has sustainability courses representing only $10 \%$ of all offered courses, then the institution will receive 4 points instead of the full 8 points. 


\section{Literature Review}

\section{Theoretical Framework}

Theory of transactionalism. Dewey and Bentley's (1946) theory of interactions and transactions suggests that human behaviors and knowledge can be attributed to the environment. This theory suggests that knowledge can be obtained from observation, such as retaining information solely from interactions with surrounding landscapes, fixed locations, or built environments. Dewey and Bentley define this relationship between person and environment as being part of the same system, describing this system as the "knowings and knowns (knowing-men and things-known)," "observed and the observer," and "named and the naming."

Our position is simply that since man as an organism has evolved among other organisms in an evolution called "natural," we are willing under hypothesis to treat all of his behavings, including his most advanced knowings, as activities not of himself alone, nor even as primarily his, but as processes of the full situation of organismenvironment. (p. 506).

The contributions of Phillips, Tibbels, and Patterson (2013) to the theory of transactionalism further explain how interactions and transactions between person and place can be applied to education. Phillips et al. interpret Dewey's transaction theory by stating, "each member of the human race is a transactional system, through which relationships are worked out with the environment." According to Phillips et al., transactionalism is a communication system between man and environment. The idea of transactionalism as a system was further expanded through the model of the "transactionally-viewed man," which declares, "man is an information-processing, 
organizing, open-energy system ... characterized by creatable possibilities, brought into being through transactions with the environment" (Phillips et al., 2013).

In regards to this project, the knower and known are college students and their campus environment. As students interact with their campus by physically walking through the halls, taking classes, and joining clubs, a transaction of information occurs between them and their experiences. This transaction of information is the process of absorbing knowledge from the "interpenetrating relationship between objection conditions and subjective experience" (Thorpe, Edwards \& Hanson, 1993). The presence of cogeneration plants, campus gardens, recycled water signs, LEED buildings, alternative transportation incentives, waste-reduction programs, vegan and vegetarian food options, fair trade products, student environmental leadership opportunities, etc. are all examples of sustainability efforts that each student is exposed to or engages with at one point or another during their academic career. Exposure to these sustainability efforts inadvertently offers empirical knowledge on the sustainable campus qualities, thus serving as a learning platform for students by demonstrating their benefits and importance.

Experiential learning theory. There is a substantial difference between inadvertently learning through exposure to a campus's sustainability efforts versus learning through first-hand experience. Inadvertent learning exposures include any campus environmental management, such as programs and operations, to minimize energy and material consumption. First-hand experiences include any studentincorporated campaigns such as offering free alternative transportation, encouraging the 
utilization of reusable bottles to promote a zero-waste lifestyle, offering school credits for volunteering in the campus gardens, environmental-based classes, and campus government positions. These examples of first-hand experiences not only promote sustainable lifestyles but also teach students the personal and global benefits of their actions through a positive feedback loop as illustrated by Kolb's (1984) experiential learning theory.

There is an epistemological agreement that believes behavior is determined by an individual's positive reoccurring experiences (Dewey \& Bentley, 1946; Dewey, 1938; Kolb, 1984; Lewin, 1939). David Kolb drew from Lewin and Dewey’s separate experiential learning model when formulating his own. Kurt Lewin describes the learning process as a four-stage cycle explaining how (1) "concrete experience" provokes (2) "observations and reflections," which then causes the (3) "formation of abstract concepts and generalizations," ending at the last stage of (4) "testing implications of concepts in new situations" (Kolb, 1984). By applying Kolb's experiential learning theory, students may develop a positive attitude towards an experience, consequently changing their current patterns to pro-environmental behavior.

Environmental affordance theory. Universities play a crucial role in preparing students for the future. Universities are obligated to provide resources and assistance to their students to achieve success during and after their schooling. The resources provided by college campuses afford students the chance to complete a successful academic journey. According to James Gibson's (1979) environmental affordance theory, an individual's behavior is limited to their environment. The affordances of one's 
environment are what it offers, provides, or furnishes (Gibson, 1979). Gibson uses affordances to describe the "possibilities or opportunities" for action and behaviors. Ajzen (1991) would agree with Gibson's theory by also illuminating how "resources and opportunities available to a person must to some extent dictate the likelihood of behavioral achievement" (Ajzen, 1991). For example, a small rock affords throwing or grasping, while a tree that is "perceived as climb-on-able" affords climbing-on (Fjørtoft, 2001). A tree may also afford shade, food or shelter for a variety of species depending on the perceived need at the time. There is no "correct" use of the tree, "only the affordances perceived by the various perceivers" (Sadler \& Given, 2007).

In one research study by Sadler and Given (2007), the environmental affordance theory was used to interpret how graduate students perceived information afforded to them by their library. The types of "information" were the library's "books, databases, instructional sessions, librarians, [and] physical space[s]" (Sadler \& Given, 2007). They found that some of the information was perceived differently than how the libraries intended. Although the graduate students perceived the information differently, they were still able to conduct research and perform well on their assignments. To summarize, the access to library information, however intended to be perceived, still helped the students with their schoolwork. Overall, the accessibility of information affords students the chance to be educated on the subjects they desire. Normally, any remodeling or retrofitting efforts made by a university are only intended to meet specific sustainability goals, yet if a school affords students the chance to learn and educate themselves on 
sustainability through first-hand examples, then students will then have more opportunity to do so.

\section{Implications for Universities}

Universities have a significant role in contributing to a brighter and cleaner future. This exact role is best described as Campus Sustainability. Valazquez et al. (2006) give meaning to the term Campus Sustainability through their explanation of a sustainable institution:

A higher education institution, as a whole or as a part, that addresses, involves and promotes, on a regional or a global level, the minimization of negative environmental, economic, societal, and health effects generated in the use of their resources in order to fulfill its functions of teaching, research, outreach and partnership, and stewardship in ways to help society make the transition to sustainable lifestyles. (p. 812)

It is important to hold universities accountable for their means of production to ensure a healthy campus environment. With their immense spending power, universities have their fair share of potential significant environmental impacts and need to uphold certain social and environmental responsibilities (Cole, 2003). Alshuwaikhat \& Abubakar (2008) compare universities to that of hospitals and mega-hotels in terms of waste generation, water, and material consumption, burning of hydrocarbon fuels for operating machinery, heating and lighting, and transportation. Each of these methods of operations has tremendous implications for environmental quality. Alshuwaikhat \& Abubakar (2008) mention that until recently, environmental impacts having to do with universities may have been overlooked. These impacts include complex operations having to do with hazardous materials through laboratory use and regular grounds maintenance. With environmental impacts like these, enforcing or encouraging campuses to become 
sustainable is all the more critical. Lindsay Cole (2003) offers another glimpse into the idea of sustainable campuses through her definition:

A sustainable campus community acts upon its local and global responsibility to protect and enhance the health and well-being of humans and ecosystems. It actively engages the knowledge of the university community to address the ecological and social challenges that we face now and in the future. (p. 30)

Creating ecologically sound communities begins with equipping students and the rest of society with the appropriate knowledge, skills, tools, and experiences (Wang et al., 2013). Understanding the urgency to transform from unsustainable to sustainable patterns has been mostly due to academics. According to Wang et al. (2013), shifting to a new sustainable form of developing has been "based largely upon academic catalyzation of the needed changes."

Since the EPA mandated colleges and universities to follow the same standards as industries (Schaeffer, 2000), universities have been much more forward-thinking in their environmental planning strategies to meet the federal environmental requirements. As corporations have "corporate social responsibility" (CSR), Shek and Hollister (2017) argue that the same social responsibility applies to universities. Shek and Hollister (2017) explore the mission of "university social responsibility" (USR) through many examples, such as the promotion of ethical and beneficial activities to the public; promotion of environmental conservation; sustainability and a balanced social development; and provisions of support to the "needy and vulnerable populations."

Unlike corporations, where the goal is to maximize profits instead of providing educational services like that of universities (Shek and Hollister, 2017), universities across the nation have implemented new operations and procedural practices to reduce 
their ecological footprints (Uhl \& Anderson, 2001; Wang et al., 2013). Uhl and Anderson (2001) offer a framework for practical and feasible ways to lower the ecological footprint of universities that include: fossil fuel independence, ending material waste, abiding by land ethics, creating green buildings, guaranteeing ecological literacy, prioritizing research on sustainability, conserving water resources, and purchasing only from sustainable food sources. For each of these categories, many universities have found strategic ways to implement changes or mitigate particular environmental stress. The following examples are of universities in each category that have taken steps to demonstrate leadership in sustainability and climate action.

Fossil fuel independence: Uhl and Anderson (2001) refer to State University of New York (SUNY) at Buffalo to illustrate the benefits of retrofitting lights and upgrading heating and cooling systems. In only eight years, SUNY Buffalo reduced its energy consumption by 20 million kilowatts by making said improvements to its campus fixtures.

Waste: An example of material waste reduction is the efforts of the University of California San Francisco (Fleischer, 2017). In 2017, UCSF diverted about 74\% of waste from landfills by increasing recycling and composting endeavors. UCSF created a recycling and waste reduction website with the intention to reach its zero-waste goal by 2020. The website is mobile-friendly and provides a free and user-friendly resource to effectively educate students and staff on how certain products and materials should be reused, recycled, composted, or discarded for a landfill (Fleischer, 2017). 
Land Ethic: The concept of land ethics most notably comes from Aldo Leopold's (1953) famous remark, "A thing is right when it tends to preserve the integrity, stability, and beauty of the biotic community. It is wrong when it tends otherwise." When land is set aside for the sole purpose of preservation, it can encourage pride and respect for the community and the history of the land (Uhl \& Anderson, 2001). The University of California, Davis developed a 100-acre arboretum along the old north channel of Putah Creek (UCD, 2017). Its Arboretum holds 22,000 trees and plants, serving as a platform for teaching and promoting sustainable horticulture (UCD, 2017).

Green Buildings: Elon University, located in central North Carolina, has a total of twenty-five LEED-certified buildings within its campus (Durr \& Althen, 2015). Many sustainable features are present in the LEED-certified buildings such as storm-water collection systems, sedimentation, and erosion preventatives, surrounding bike racks, native vegetation landscapes, low-flow plumbing fixtures, natural lighting, recycled material building content, and advanced heating ventilation and air conditioning systems made to respond to outdoor conditions.

Ecological literacy: Ecological literacy, otherwise known as EL, is a product of environmental education and green curricula. Universities that have a goal of sustainability should guarantee EL for all students to instill an earth-conscious population after graduation. Rowe (2002) discusses sustainability-related core requirements that some universities and colleges have incorporated within their curricula. For example, since 1988, the University of Northern Iowa requires undergraduates to take the course "Environment, Technology and Society" as a requirement to graduate. Another example 
that Rowe (2002) mentions is Alverno College, located in Milwaukee, Wisconsin. Alverno College has required its students, for the last twenty-five years, to take the course, "Globally Effective Citizen," which teaches "sustainability perspectives and change agent skills.”

Research: In 2018, the University of New Hampshire (UNH) received full credit for the STARS category, "Support for Research." UNH has multiple ongoing, academic programs that encourage students and faculty to research sustainability. Programs for students include sustainability fellowships, internships, awards, and scholarships. These programs are offered through various UNH organizations such as The Sustainability Institute, the Carsey School of Public Policy, and more. UNH offers faculty a development program known as The Engaged Scholars Academy, which fosters and supports faculty research related to sustainability.

Water: Within the latest version of the STARS report, Stanford University reported that in the last fifteen years, the school has replaced more than 13,000 academic and student housing bathroom fixtures with water-efficient models, such as low-flow showerheads, sink aerators, and high-efficiency toilets and urinals. Standard irrigation controls were also converted to weather-based irrigation controls, which, in addition to retrofits, has decreased irrigation water use by $45 \%$ since 2013 . With these efforts combined, Stanford University has managed to reduce potable water usage by $49 \%$, equivalent to saving 1.3 million gallons of water per day.

Food: Sustainable dining incorporates "real food." According to the organization The Real Food Challenge, "real food" nourishes producers, consumers, communities, and the 
earth. In short, sustainable food is harvested locally, fair trade, organic, and cagefree/grass-fed. Within its sustainable dining policy, the University of Santa Barbara (UCSB) is committed to procuring 20\% sustainable food products by the year 2020 . Currently, UCSB hosts on-campus farmers markets to increase student, staff, and faculty access to fresh and local produce. UCSB also offers vegan dining options every meal in all dining commons, as well as within an online dietary tool, called NetNutrition. NetNutrition "allows individuals to view nutritional information about items and filter food based on dietary preferences, such as vegan and vegetarian, by dining location" (UCSB STARS report, 2018).

The extent of these examples reaches far beyond the scope of this section. Every type of effort or STARS requirement that is addressed by just one university for one category is extraordinarily impressive. Many universities use conventional tactics (retrofitting projects, LEED buildings) to become more environmentally friendly, yet each university also uses tactics that are unique, individualistic, and specific of their own culture. An indepth investigation of these campus-wide sustainability tactics is crucial for creating an environmentally literate society and a sustainable future. The lengths that many colleges will go to tackle climate change serve as an example for all aspects of society, regarding policies and government action.

\section{Environmental Education}

In 1977, environmental educators all over the world attended the United Nations Intergovernmental Conference on Environmental Education in the city of Tbilisi to establish definitions on environmental education with intentions of developing an 
international education program (Tbilisi Intergovernmental Conference on Environmental Education, 1978). They concluded the objective of EE as:

Environmental Education should aim at creating awareness, behavioral attitudes and values directed towards preserving the biosphere, improving the quality of life everywhere as well as safeguarding ethical values and the cultural and natural heritage including: holy places, historical landmarks, works of art, monuments and sites, human and natural environment, including fauna and flora and human settlements. (1978, p. 30)

The opening remark by Uhl and Anderson (2001) in their literature on "greening universities" perfectly encapsulates the stress on universities to simultaneously teach environmental resolutions to their students and to also be a mitigation to the issues as well: "Even as universities teach their students that the vital signs of the Earth are in decline, graduates leave college to begin lives that generally contribute to, rather than mitigate, a growing array of environmental and social problems." Dewey and Bentley's (1946) transaction theory suggests that both of these roles, exemplar and educational, provide students with the same opportunities to learn. The "unfractured observations" made by students either in the classroom or on campus, "by whatever merits or defect," will be processed accordingly and, therefore, will incidentally contribute to the individuals' growth of knowledge (Dewey \& Bentley, 1946). Courses and curricula must be transformed by the educators "to engage and empower students to learn and apply new sustainable development concepts, paradigm knowledge, and wisdom to achieve the necessary societal transformations" (Wang et al., 2013).

\section{Environmental Literacy}

The term "environmental literacy" made its debut in an article of the Massachusetts Audubon in 1969 (Roth, 1992, 1969). The term garnered little attention until the 
following year, when President Richard Nixon's speeches regarding the first National Environmental Education Act began to reference "environmental literacy" (Roth, 1992). According to the refined definition by Charles Roth (1992), EL is described as the "capacity to perceive and interpret the relative health of environmental systems and to take appropriate action to maintain, restore, or improve the health of those systems." The overwhelming importance of being environmentally literate or having an environmentally literate global populace is highlighted in its own definition “... to improve the health of those systems." The overall health of the planet is unquestionably deteriorating, yet proper environmental education may be mitigation to slowing Earth's decline (Rillo, 1974). To ensure environmental protection, Rillo (1974) describes that "what is needed is an aware, articulate, and activated citizen who is willing to donate time, energy, and resources toward the solution of environmental problems." The core objective of environmental education is to generate an environmentally literate society, and in doing so, improve the overall health of the planet.

What does EL look like in everyday practice? Many educators have outlined specific personal attributes and indicators of an environmentally literate person. Milton McClaren (1989) offered a broad glimpse into EL when he described it as the ability to think about systems, to forecast or think ahead, to critically value issues, and to move from awareness to knowledge and action (McClaren, 1989). The Federal Interagency Committee on Education (FICE) described an environmentally literate person as one who demonstrates "awareness and sensitivity to the total environment" and possesses a "variety of experiences in and a basic understanding of environmentally associated problems." 
Additionally, an environmentally literate person has acquired a "set of values and feelings of concern for the environment, and the motivation for actively participating in environmental improvement and protection" (FICE, 1978). Thomas Rillo characterizes EL by emphasizing one's ecological "understanding of the biophysical world." Rillo explains the importance of identifying the "biosphere (natural environment) and the psychosphere (the man-made environment) and the role of these resources in contemporary society." Overall, EL depends on one's capabilities to recognize ecological problems enough to understand a solution and accept "responsibility for the solution of the problems as a basic civic duty" (Rillo, 1974).

Measuring EL will help understand the status of individual knowledge on the environment while also serving as an indicator of current societal and educational levels in regard to the health of the planet (Roth, 1992). When formulating a sufficient measuring tool, it is important to consider the six major aspects of EL: (1) environmental sensitivity, (2) knowledge, (3) skills, (4) attitudes and values, (5) personal investment, and (6) responsibility and active involvement (Roth, 1992). Many studies have combined these six areas of EL into three clearly defined and measurable criteria: (1) knowledge, (2) attitude and (3) behaviors (Bogan \& Kromrey, 1996; Fah, 2014; Green, 1997; Kibert, 2000; NEETF, 1998; O’Brien, 2007; Pe'er, 2007; Yumusak et al, 2016). Figure 1 illustrates how the original six EL categories were combined into three dimensions of EL. 


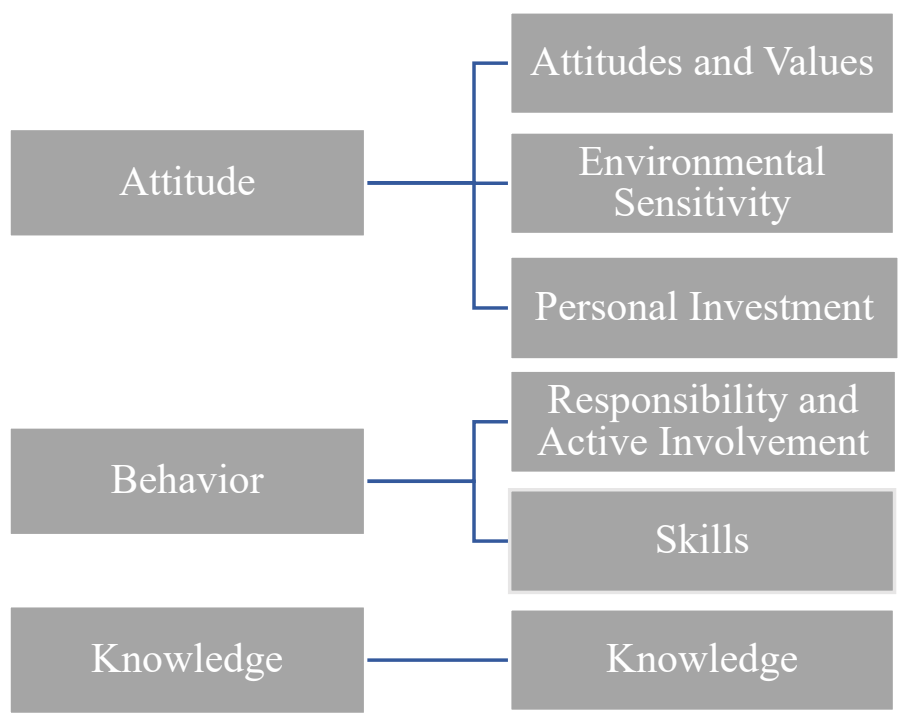

Figure 1. Three dimensions and six attributes of EL.

The Wisconsin Environmental Survey measured student EL in three sections:

affective, behavior, and cognitive (Champeau, 1997). Each of these sections are defined as part of their school-wide EL framework (Champeau, 1997):

- Affective subscale: dealt with attitudes, locus of control, and assumption of personal responsibility for environmental quality.

- Behavior subscale: allowed for an actual self-reporting of student behaviors related to the environment.

- Cognitive subscale: assessed student awareness and knowledge related to ecology, the environment, and environmental issues. 
Dimensions of environmental literacy: A positive attitude towards the environment, coupled with environmental behavior and knowledge make up the three pillars of EL. These three pillars act as the trinity of environmentalism. Too often does one dimension predict the outcome of the others. Without an initial experience, behaviors are stifled and attitudes may not form (Ajzen, 1991; Dewey \& Bentley, 1946; Dewey, 1938; Fishbein \& Ajzen, 1975; Kolb, 1984; Lewin, 1939). An individual who is aware of environmental issues and develops a personal concern for the environment will often engage in behavior that is conducive to a sustainable lifestyle (Maloney \& Ward, 1973). Meinhold and Malkus (2005) discovered that "pro-environmental attitudes" significantly predict "proenvironmental behaviors."

Furthermore, EK acts as a "significant moderator between environmental attitudes and environmental behaviors" (Meinhold \& Malkus, 2005). Maloney and Ward (1973) stressed the importance of determining "what the population 'knows' regarding ecology, the environment, and pollution [and] how they feel about it... these are necessary antecedent steps that must be made before an attempt can be made to modify critically relevant behaviors." Thus, the measurability of EL depends on accurately appraising an individual's levels of attitude, knowledge, and environmental behaviors.

Attitude towards the environment: The first dimension of EL is attitude. A positive attitude towards the environment initiates assurance for the environment. Environmental assurance reflects "the attitude that there is hope for a sanative environment and that mankind has both the desire and the capability of achieving it" (Rillo, 1974). Without 
environmental assurance, apathy and pessimism will prevail, which does absolutely nothing constructive toward the restoration of a quality environment (Rillo, 1974).

Several studies have measured attitudes towards the environment as an indicator of EL (Dunlap et al., 2000; Meyer \& Frantz, 2001; Schultz, 2001; Schultz et al., 2004). These authors do not always explicitly use the term "environmental literacy" as different variations of the term have been used in the past. For instance, Dunlap et al. (2000) used the term "pro-ecological orientation" to describe an individual who "sees the world ecologically" and thereby, carries an understanding and appreciation for the delicate intricacies of the environment. Meyer and Frantz (2001) suggest that one's connectedness to nature is a predictor of altruistic or "ecological behavior." Dunlap et al. (2000) and Meyer and Frantz (2001) all use attitude-based survey questions to gauge their participants' overall attitude towards nature. Greenwald, McGhee, Schwartz, and Kruglanski's (1998) Implicit Associations Test (IAT) attempted to measure "relative implicit attitudes," which uses a categorical word association approach, rather than an actual survey. Greenwald's et al. (1998) IAT was later modified by Schultz, Shriver, Tabanico, and Khazian (2004) to specifically measure attitudes towards nature. The participants of the reformed IAT were asked to associate the words "me" or "not me" with words associated with the natural environment (animals, trees) vs. the built environment (car, city).

Another measurement of EA is Schultz's (2001) Inclusion of Nature in the Self (INS) scale. The INS question reads as: "I am concerned about environmental problems because of the consequence for (blank)." The participants must rate the 12 listed items 
from 1 (not important) to 7 (supreme importance). The items are separated into three different categories: (1) egoistic concerns (me, my health, my lifestyle), (2) altruistic concerns (all people, children), (3) biospheric concerns (plants, marine life, animals).

"Whereas science literacy, for many people, seems to be built on a mechanistic paradigm, environmental literacy builds on an ecological paradigm" (Roth, 1992). Dunlap (2000) created just that: the New Ecological Paradigm (NEP), a 15-question, Likert-type survey that measures "primitive beliefs" towards the environment. Primitive beliefs refer to an individual's core belief system on fundamental truths about the physical and social reality of humanity's relationship to the Earth (Rokeach, 1968). Meyer and Frantz (2004) argue that determining primitive beliefs, although important, is not an adequate measurement of one's personal relationship to the natural world. Meyer and Frantz' (2004) Connectedness to Nature Scale (CNS) measures EA by ways of affective experience, while the NEP (Dunlap, 2000) measures cognitive beliefs. Meyer and Frantz (2004) explain that NEP items such as "We are approaching the limit of the number of people the earth can support" and "Humans are severely abusing the environment" are both cognitive beliefs about humans. An example of a CNS item, such as "I often feel part of the web of life" or "I often feel a kinship with animals and plants" actually measure an individual's personal relationship and emotional response to nature. Despite their differences, both the NEP and CNS has been tested and re-tested both for validity and reliability and have proven to have internal consistencies with predicting lifestyle patterns. 
Environmental behavior: The main objective of having an environmentally literate citizenry is to have individuals who are "competent to take action on critical environmental issues" (Hungerford \& Tomara, 1977). Taking action to ensure a healthy ecosystem is evidence of EB.

Banerjee and McKeage (1994) argue that an indicator of EL is a change in lifestyle that reflects environmentalism. Hungerford and Peyton (1976) pioneered environmental, behavioral thought when describing appropriate actions in categories: persuasion (letter writing, debate), consumerism (boycotting certain goods), political engagement (lobbying, voting), and eco-management (reforestation, urban landscaping). Consumption behaviors should change as a product of increased EL, such as using alternative modes of transportation instead of driving alone, and reusing or repairing products instead of immediately discarding items (Banerjee \& McKeage, 1994). Environmental activism behaviors, such as "signing petitions, joining environmental organizations, and keeping abreast of current environmental development," are all consequences of EL (Banerjee \& McKeage, 1994). Rillo (1974) emphasized what is truly needed from "millions of people" is "action programs leading to the solution of the environmental problems confronting modern society." Of the three subsections, proecological behaviors directly set a course of action towards pursuing a solution to the “ecological crisis" (Maloney \& Ward, 1973).

Within their Ecology Scale, Maloney and Ward (1973) created the first EB measurement consisting of 36 true/false response format items. Their ecology scale contains separate attitude, behavior, and knowledge sections, resembling one of the first 
EL measurements. Within Maloney and Ward's (1973) ecology scale behavioral subsection, participants answered "true" or "false" to questions such as "I have switched products for ecological reasons" and "I save some waste material for recycling." Maloney and Ward (1973) concluded in their studies that "most people say they are willing to do a great deal to help curb pollution problems and are fairly emotional about it, but, in fact, they actually do fairly little." Similar to Maloney and Ward's (1973) ecology scale, Florian Kaiser (1998) created his own General Ecological Behavior scale (GEB). GEB consists of 40 items using yes/no response format, (i.e., "I use phosphatefree laundry detergent" and "I usually buy milk in returnable bottles)." Over the years, GEB has been modified by Kaiser and his colleagues to further investigate ecological behavior (Kaiser et al., 1999). Beside yes/no formatted response items or true/false responses (Maloney et al., 1975), Champeau (1983) measured behavior using Likert-type scale responses to better indicate the degree of agreement with a strongly-worded statement.

Environmental knowledge: EK should provoke ecological sensitivities that may lead to pro-environmental behaviors, such as policy change or eco-friendly lifestyle changes. Roth (1992) explains how EK is essential for having a functioning environmental literate society:

Functional environmental literacy indicates a person with a broader knowledge and understanding of the nature of and interactions between human social systems and other natural systems. They are aware and concerned about the negative interactions between these systems in terms of at least one or more issues and have developed the skills to analyze, synthesize, and evaluate information about them using primary and secondary sources. (p. 26). 
The thought of producing an environmentally knowledgeable citizenry has always been the driving force behind the growing phenomenon of environmental education. The sole purpose of environmental education is to create an enlightened society on the relationship between humans and nature. Whether the credit is owed to environmental education pioneers such as John Muir (1838-1914), known as "father of the national park", Aldo Loepold (1887-1949), the "father of wildlife ecology," Rachel Carson (1907-1964), who is credited for laying the foundation of modern environmentalism or Jacque Cousteau (1910-1997), the famous explorer and conservationist, environmental education continues to serve as the preliminary force for cultivating a knowledgeable society on environmental issues.

In consideration of the EK components for the Wisconsin Environmental Literacy Survey, Perri (1996) based the "cognitive" section outcomes on the components of EL composed by Iozzi, Laveault, and Marcinlowski (1990). Perri (1996) lists the EL knowledge outcomes as knowledge in ecological principles, action strategies, understanding environmental problems and issues and skills for creating, evaluating, and implementing an action plan. 


\section{Problem Statement}

Most environmental issues originate from human activities (Crutzen, 2006; Goudie, 2013). Human effects on the Earth's atmosphere, for example, have caused a dramatic shift in climate patterns (Wang \& Chameides, 2007). Although some scientists speculate that many effects of climate change are irreversible, a surge of green power movements, environmental protection agencies and sustainability rating systems have surfaced throughout the world. Unfortunately, even in the wake of mitigation efforts, environment degradation persists. The lack of environmental concern, awareness, and education is partly to blame. As a result, researchers theorize about humans' psychological relationship to the natural world being an indicator of increased ecological behavior (Fisher, 2002; Mayer, 2004; Roszak, 1995). An individual who exemplifies ecological behavior and attitude is considered to be environmental literate (Roth, 1992). EL refers to the capacity of an individual to behave environmentally and understand how those behaviors have an impact on the ecology of natural systems (Roth, 1992). A comparison between student EL and a university's sustainability rating will help illuminate a connection, if any, between environmental education and sustainable development.

The STARS survey provided by AASHE does not include the EL of the student body. It is important to develop an understanding as to whether or not the initiatives that STARS and non-STARS-rated schools are integrating have an impact beyond their immediate ecological footprint. Are these programs actually having an impact on the student populations' understandings of these issues as well as their attitudes towards the environment? Many studies have proven that access to nature and open spaces are linked 
to EL and increased connectedness to nature, yet there is little to no available research connecting the relationship between built environments and EL (Heerwagen, 2009; Mayer \& Frantz, 2004).

The purpose of this project was to analyze the relationship between college campuses and student EL by surveying students attending a range of STARS- and non-STARSrated schools. The results of this study represent an analysis of the relationship between a school's sustainability efforts with individual student environmental awareness and an overall positive attitude towards the environment. Determining which sustainability programs and conservation tactics most positively affect rates of student EL provides information for colleges to help determine where to best focus their planning and development efforts, thus creating a positive loop of information and best practices. 


\section{Research Objectives and Questions}

The purpose of this study was to analyze the relationship between the EL of college students and university STARS scores. Additionally, this project compared student EL from STARS-rated schools and student EL from non-STARS-rated schools. Measuring EL consisted of compiling scores from three components: attitude towards the environment, knowledge of environmental issues, and environmental behavior. Lastly, this study analyzed the extent of the relationship between EA, EB, and EK among college students and illuminated how students' EA and EK contribute to their EB.

Research Questions:

Q1. What is the relationship between university STARS-rating and environmental literacy?

Q1a. How does student environmental literacy differ between STARSand non-STARS-rated schools?

Q1b. How does student environmental literacy differ amongst STARSrated schools (Bronze, Silver, Gold, Platinum)?

Q2. What is the extent of the relationship between environmental knowledge, environmental attitude, and environmental behaviors among college students? 


\section{Methods}

\section{Subjects}

The participants in this study were undergraduate and graduate university students attending STARS- and non-STARS-rated schools within California, United States. In terms of undergraduates, only sophomores, juniors, and seniors participated in the survey. First-year students (freshmen), who have only been recently matriculated into the school system, were not viable participants. Because the theory of transactionalism (Dewey \& Bentley, 1946) involves individuals who have grown accustomed to their environment, first-time freshmen, transfer students, and first-year graduate students from different undergraduate schools were exempt from participation (being new to their campus and therefore lacking the adequate exposure for full acclimation). For these same reasons, only four-year universities were selected for participation, while community or junior colleges were exempt. Respondents represented a variety of majors, including environmental and non-environmental majors. This project was intended to target college students who are likely to vary among demographics regarding age, gender, race, or ethnic background.

\section{Study Site}

The state of California holds the most STARS-rated schools in the nation, allowing the state to be a quintessential location to study a variety of students. As of February 2018, STARS had been conducted on 391 campuses in the United States, whereas 39 of the total had been California schools. Coming in second, New York had 34 STARS-rated schools. The results of this study can be applied to any region with STARS and non- 
STARS-rated universities. Aside from the United States, STARS surveys have also been conducted within schools in the United Kingdom, Mexico, and Canada.

In February 2018, 8 of 39 STARS reports were considered expired since reports had not been updated within three years or more. Of the remaining 31 schools, there was one Platinum, 13 Gold, 11 Silver, 2 Bronze, and 4 Reporter schools. A “reporter" rank describes an institution that participated in the program, yet for undeclared reasons, wished to keep its scores and rank status private. Both reporter schools and schools with expired reports were exempt from participation. Table 2 lists the 26 active STARS-rated campuses from highest rating (Platinum) to the lowest represented rating (Bronze). Campus populations range from 412 students (Soka University of America) to over 40,000 students (California State University, Fullerton). These schools (Table 2) served as the initial sampling pool for retrieving data based on their STARS rank.

According to Table 2, Stanford University is the only school ranked Platinum. Therefore, only students from Stanford University were surveyed to assess EL from a Platinum-rated college. Following suit, Sonoma University and Soka University of America were initially the only schools in California ranked Bronze, and therefore, the only schools surveyed to assess EL from a Bronze-rated college. Of the 13 Gold-rated schools, three schools were selected using convenience sampling. Of the 11 Silver-rated universities, three schools were randomly selected to be surveyed. 
Table 2

List of all STARS-Rated Universities in California as of February 2018

\begin{tabular}{|c|c|c|c|}
\hline & School & Rank & Population \\
\hline 1 & Stanford University & Platinum & 16,336 \\
\hline 2 & Santa Clara University & Gold & 8,770 \\
\hline 3 & Humboldt State University & Gold & 8,503 \\
\hline 4 & University of California, Santa Barbara & Gold & 24,346 \\
\hline 5 & San Jose State University & Gold & 32,154 \\
\hline 6 & California State University, Sacramento & Gold & 30,510 \\
\hline 7 & University of California, Riverside & Gold & 21,539 \\
\hline 8 & University of California, Santa Cruz & Gold & 18,783 \\
\hline 9 & California State University, Northridge & Gold & 39,916 \\
\hline 10 & University of California, Merced & Gold & 7,325 \\
\hline 11 & Pitzer College & Gold & 1,067 \\
\hline 12 & Pomona College & Gold & 1,703 \\
\hline \multirow[t]{2}{*}{13} & California State University, Channel & & \\
\hline & Islands & Gold & 7,034 \\
\hline 14 & California State University, Long Beach & Silver & 37,776 \\
\hline 15 & California State University, San Marcos & Silver & 13,144 \\
\hline 16 & Mills College & Silver & 1,405 \\
\hline \multirow[t]{2}{*}{17} & California State Polytechnic University, & & \\
\hline & Pomona & Silver & 25,326 \\
\hline 18 & University of the Pacific & Silver & 6,128 \\
\hline 19 & California Polytechnic State University & Silver & 21,306 \\
\hline 20 & San Francisco State University & Silver & 29,045 \\
\hline 21 & California State University, Monterey Bay & Silver & 7,274 \\
\hline 22 & California State University, Los Angeles & Silver & 27,827 \\
\hline 23 & Saint Mary's College of California & Silver & 4,109 \\
\hline 24 & California State University, Fullerton & Silver & 40,235 \\
\hline 25 & Soka University of America & Bronze & 412 \\
\hline 26 & Sonoma State University & Bronze & 9,323 \\
\hline
\end{tabular}

Note. University Ranks: Data derived from the AASHE STARS website.

Source: Data collected from AASHE STARS (2017).

Table 3 lists the final sample of selected universities chosen to gather surveys for this study. A total of 12 schools were contacted and asked to participate in this study. A breakdown of the 12 schools is follows: 1 Platinum-rated school, 3 Gold-rated schools, 4 
Silver-rated schools, 1 Bronze-rated school, and 3 non-STARS-rated schools. Figure 2 displays the geographical locations of each university throughout California. While the initial sample design included an equal amount of Silver- and Gold-rated schools (three Silver, and three Gold), Soka University of America had submitted an updated STARS report in June 2018 and received a Silver-rating. The contacted faculty and staff from Soka University believed Soka was considered a Silver category school for the remainder of the project. Consequently, data from Soka University were used to assess student EL from Silver-ranked schools instead of Bronze-ranked schools. The addition of Soka University to the Silver category brought the total schools surveyed within the Silver category to four schools, and the total number of schools in the Bronze category to one.

Table 3

\section{List of Schools by STARS Rank}

\begin{tabular}{lll}
\hline & School & Rank \\
1 & Stanford University & Platinum \\
2 & California State University, Northridge & Gold \\
3 & San Jose State University & Gold \\
4 & University of California, Riverside & Gold \\
5 & Cal State Polytechnic University, Pomona & Silver \\
6 & California State University, San Marcos & Silver \\
7 & San Francisco State University & Silver \\
8 & Soka University of America & Silver \\
9 & Sonoma State University & Bronze \\
10 & California Baptist University & Non-rated \\
11 & San Diego State University & Non-rated \\
12 & University of California, Berkeley & Non-rated \\
\hline
\end{tabular}

Note. University Ranks from the AASHE STARS website.

Source: Data collected from AASHE STARS (2017). 

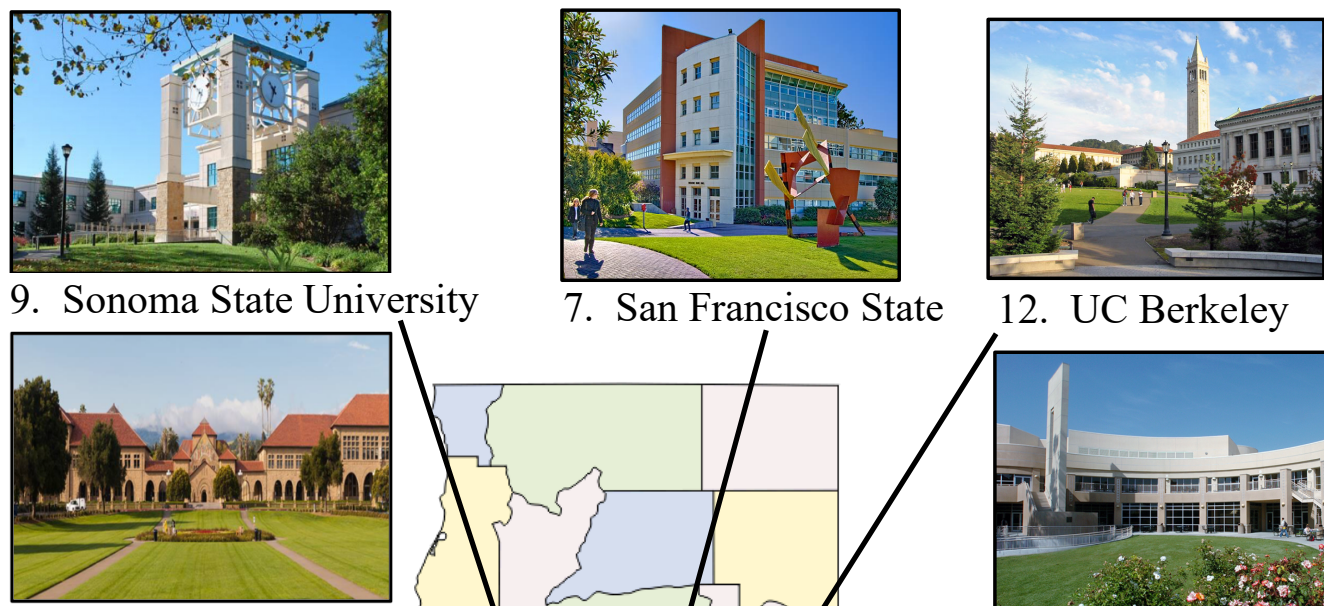

7. San Francisco State

12. UC Berkeley
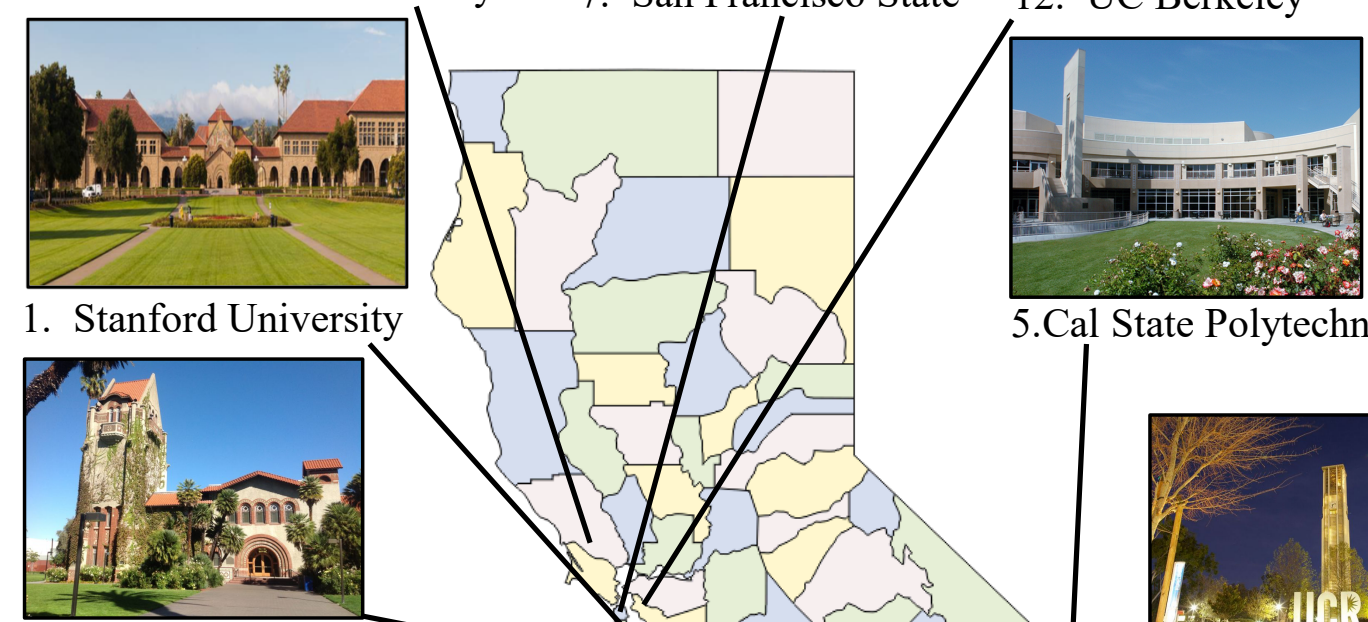

2. San Jose State

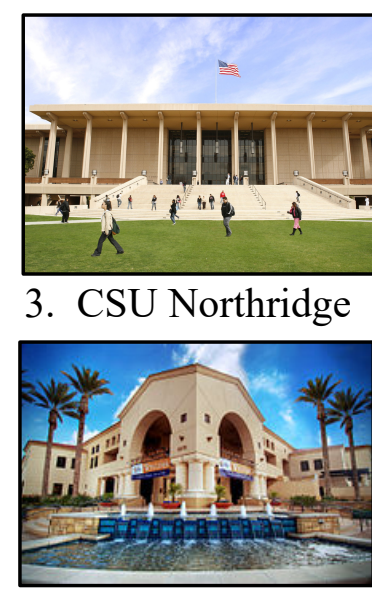

10. Cal Baptist University

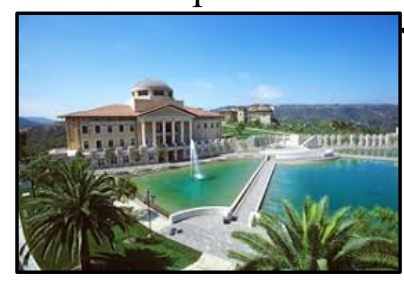

8. Soka University

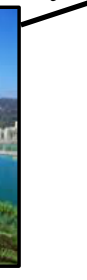

(1)

Figure 2. Geographical locations and photos of the surveyed universities across

California. Source: Map and photographs adapted from Google Image. 


\section{Instrumentation}

This study used an adaptation of Champeau's (1997) Wisconsin Environmental Survey (WES) to measure the three separate dimensions of EL (attitude, behaviors, and knowledge). WES is originally known as the Wisconsin High School Student Environmental Survey (WHSSES). With the guidance from the Wisconsin Environmental Education Board and the Wisconsin Department of Public Instruction, the Wisconsin Center for Environmental Education (WCEE) developed WES as a statewide survey to assess EL in Wisconsin K-12 schools. The goal of the survey was to provide feedback to educators to improve the quality of environmental education for their students (Champeau, 1997; Peri, 1996; Quale, 1992). Since its development, WES has been used by several researchers to successfully measure EL (Champeau, 1997; Green, 1997; Hsu \& Roth, 1998; Kibert, 2000; Todt, 1995).

In 1997, Green (1997) modified WES from the original version, WHSSES, to better suit adult participants, rather than high school students. In Green's modified WES, as well as the original WHSSES, the three measures of EL are (1) affective, (2) behavior, and (3) cognitive. Just as Kibert (2000) amended Green's version of WES to "reduce the use of technical jargon," the original measures were renamed to "environmental attitude" (affective), and "environmental knowledge" (cognitive), while "behaviors" will be left as is. The original WHSSES is 90 questions long with 33 items under the attitude subsection, 15 items under the behavior subsection, and 43 knowledge subsection items. Kibert (2000) further modified Green's survey by reducing the original survey to 45 questions, with 15 questions belonging to each of the three subsections. Following the 
example of the New Ecological Paradigm (Dunlap, 2000), the survey questions that were used for this project were further condensed to no more than 20 questions. To minimize survey fatigue, the survey utilized by this study had a total of 15 questions with five questions for each subsection (not including background questions such as class standing, gender, major, and age).

The entirety of the survey was based on Bloom's (1956) taxonomy of educational objectives (Peri, 1996; Quale, 1992). The items on Champeau's (1997) original WHSSES were chosen with careful consideration from the WES advisory committees. Each of the subsections (attitude, behavior, knowledge) were heavily researched and examined for the development process of the survey items. Notable authors such as Dunlap and Vanliere (1978), Horvat and Voelker (1978), Iozzi (1978), Maloney et al. (1975), and many others provided ideas and frameworks for the attitude survey items (Peri, 1996). Phyllis Peri (1996) references each author that provided ideas for developing WES. Based on recommendations of the WES advisory committees, a fivepart Likert-type scale was chosen to most accurately measure the attitude and behavior sections (Peri, 1996; Quale, 1992). Therefore, if the assisting research did not already use Likert-types scales, then the items were adapted to Likert-type (Peri, 1996). When formulating the behavior subsection, the measures introduced by Champeau (1983), Maloney et al. (1975), Ramsey and Hungerford (1989), and Sia (1985) proved very helpful when determining the most appropriate set of actions and behaviors to assess (Peri, 1996). The survey items for the Knowledge subsection were based on ecological principles outlined by Hungerford et al. (1980). Measures by Engleson et al. and (1985) 
Hungerford and Peyton (1976) were also reviewed to determine the best Knowledge items.

Instrument validity: The WCEE tested the original WHSSES extensively for validity based on its Environmental Literacy Framework, similar to the National Association for Environmental Education Guidelines (Green, 1997). An advisory council, "made up of individuals representing elementary and secondary classroom teachers, school administrators, university professors, the Department of Natural Resources, the Department of Public Instruction, the Wisconsin Association for Environmental Education, and the Wisconsin Education Association Council," helped determine the outline of an EL framework that would best represent the level of student EL across the state (Champeau, 1997; Peri, 1996). Test questions were developed according to student learning objectives and sent to educators for review. The items that survived the initial review "were then administered in a series of pilot tests to over 250 fifth- and eleventhgrade students" (Champeau, 1997). After the second round of pilot tests, the final instrument was constructed and used for the statewide assessment (Champeau, 1997; Peri, 1996; Quale, 1992).

\section{Survey Design}

This project is a survey study since subjects were asked to fill out a questionnaire to determine their EL. A 20-question online (SurveyMonkey®) survey was sent to students via email. The survey instrument used for this study was a modified version of WES. The survey was administered to students attending selected universities, which consisted of four sections (see Appendix B). The first section was composed of short answer 
questions asking respondents for basic demographic information such as university, major, class standing, gender, and age. The second section of the survey consisted of five Likert-type questions asking respondents about their attitude towards the environment and assessed their connectedness to nature. The attitudinal questions of the surveys were a selection of items used by Kibbert (2000) in her version of WES (Champeau, 1997). The third section of the survey consisted of five Likert-type questions asking respondents about their EB. The behavioral questions in the third section were directly based on Kibberts' (2000) version of WES (Champeau, 1997). The fourth section of the survey consisted of five multiple-choice questions on respondent EK. The knowledge items in the fourth section of the survey were a selection of items used by Kibbert (2000) in her version of WES (Champeau, 1997).

Analyzing data from each section of the survey and comparing responses between STARS-rated schools and non-STARS-rated schools helped answer the first portion of the primary research questions: Q1. How does EL differ between STARS and nonSTARS-rating schools? Using data from each section of the survey and comparing responses between students attending universities from each of the STARS levels (Bronze, Silver, Gold, Platinum) helped answer the second portion of the primary research questions: Q2. How does EL differ amongst STARS-rated schools? Comparing scores between each of the EL subsections helped answer the second research question: Q3. What is the extent of the relationship between EA, EB, and EK among college students? 


\section{Data Collection}

For each selected university, student participants were contacted via email by their professors. The student researcher contacted university professors via email (see Appendix A) to request their participation in the study. The initial email addressed the purpose of the study, confirmed their student's confidentiality, requested participation, and provided a link to the survey. The professors either emailed their students the survey link or wrote the link on the classroom whiteboard for students to complete after their class session.

Regarding the selected universities: the Silver and non-STARS-rated schools were randomly selected. The Bronze-, Gold-, and Platinum-rated universities were selected based on convenience or selected based on availability within the STARS ranks. The education departments/majors and the contacted professors within the departments were all randomly chosen in each category (Bronze, Silver, Gold, Platinum, and non-STARSrated). Each school was assigned a number to randomly select the university. Then, using a random number generator, ten groups of three random numbers were created. Each group of three was randomly assigned a number. Then, a random number was generated, thus selecting the list of schools that were surveyed. Next, the department and the professors that were sent the survey link were also randomized using a similar method. Each department or major was assigned a number. A random number generator was used to select the first departments that were contacted. For each department, the professors with an available email address were also assigned a number and chosen via a 
random number generator. About 10 - 20 professors were contacted at a time from each randomized department until the target response goal was reached.

According to the information provided by SurveyMonkey ${ }^{\circledR}$, at least 100 surveys were needed from a student population of $10,000+$ to have $a+/-10 \%$ margin of error. For a $+/-$ $5 \%$ margin of error at $10,000+$ students, 385 surveys were required. Schools with less than 10,000 students required 100 surveys for $+/-10 \%$ margin of error, yet only 370 surveys for $+/-5 \%$ margin of error. Therefore, the target response goal for this project was 150 surveys from each school in an attempt to exceed the amount for a $+/-10 \%$ margin of error. With this target in mind, the anticipated survey response rate was 1,800 responses altogether.

\section{Data Analysis}

Data were derived and quantified from the closed-ended survey questions, and then analyzed using SPSS 25 . The independent variables include the university categories (non-STARS-rated and STARS-rated: Bronze, Silver, Gold, and Platinum). The dependent variables include the EL index, the shortened version of WES. The academic variables (university, major, and class standing) are nominal measures, while the EL index is an ordinal measure (except the knowledge section is nominal) and were treated as continuous variables.

Descriptive statistics were calculated to find the frequency distribution and central tendencies of the EL variables. A Mann-Whitney U Test (the non-parametric equivalent of t-test) was used to analyze the two populations means of (1) STARS-rated schools (2) and non-STARS-rated schools, in order to find how EL differs between both groups. A 
Kruskal-Wallis test (the non-parametric equivalent of analysis of variance) was used to test whether EL differs amongst each of the STARS categories (Bronze, Silver, Gold, and Platinum). Lastly, coefficient correlations were calculated to analyze the relationship between the EL subsections, EA, EB, and EK.

\section{Quantification of Data}

The EL variables were separated into three subsections: attitudes towards the environment, environmental behaviors and actions, and knowledge about the environment. When referenced, the subsections were condensed to "attitude," "behavior," and "knowledge."

Environmental attitude subsection: The EA subsection reflected the affective subscale from WHSSES. The EA section consisted of five questions to investigate the students' environmental sensitivities and concerns. In congruence with WHSSES, the responses used a five-point Likert-type with possible responses ranging from "strongly agree" to "strongly disagree." The most positive EA response was assigned a score of four, while the most negative EA response was assigned a score of zero. The inside response options were assigned scores from 1 to 3 depending on the implied favorability to the environment. For instance:

I think most of the concern about environmental problems has been exaggerated.

$\begin{array}{ll}\square \text { Strongly Agree } & =0 \text { points } \\ \square \text { Agree } & =1 \text { point } \\ \square \text { No Opinion } & =2 \text { points } \\ \square \text { Disagree } & =3 \text { points } \\ \square \text { Strongly Disagree } & =4 \text { points }\end{array}$


A high score in the EA subsection indicated a favorable EA. The lowest possible score was zero, and the highest possible score was 20 .

Environmental behavior subsection: The EB subsection reflected the behavior subscale from WHSSES. The EB section consisted of five questions to investigate the students' environmentally responsible behavior, ecological conduct, and sustainable actions. In congruence with WHSSES, the responses used a five-point Likert-type scale, phrased as "almost always" to "never." Responses indicating a favorable EB were assigned a score of four, while responses indicating an unfavorable EB were assigned a score of zero. Inside response options were assigned scores from 1 to 3 depending on the implied favorability to the environment. For instance:

I turn off lights and appliances when they are not being used to conserve electricity.

$\begin{array}{ll}\square \text { Almost always } & =4 \text { points } \\ \square \text { Often } & =3 \text { points } \\ \square \text { Sometime } & =2 \text { points } \\ \square \text { Almost never } & =1 \text { point } \\ \square \text { Never } & =0 \text { points }\end{array}$

A high score in the EB subsection indicated favorable EB. The lowest possible score was zero, and the highest possible score was 20 .

Environmental knowledge subsection: The EK subsection reflected the cognitive subscale from WHSSES. The EK section consisted of five questions to investigate the students' knowledge of environmental problems and ecological foundations. In congruence with WHSSES, the EK question items were multiple-choice. Correct responses were assigned a score of four, while incorrect responses received a score of 
zero. A high score in the knowledge subsection indicated a high level of EK. The lowest possible score was zero, and the highest possible score was 20 .

Composite Score: The sum of each subsection scores determined EL. The lowest possible score was zero, and the highest possible score was 60 . The composite scores were compared to measure the extent of the relationship between university STARSratings and EL. 


\section{Results}

According to the results of the analyses performed on the data sets, no statistical difference was found between STARS-ranked schools and non-STARS-ranked schools regarding EL. Likewise, the relationship between EL and STARS ranks (Bronze, Silver, Gold, Platinum) was not found to be statistically significant. Furthermore, the relationship between each EL component was investigated. Attitude and behavior had a moderate relationship, while all other relationships between components were weak. Lastly, some demographic variables (gender and class standing) were found to have a statistically significant relationship with EL. Gender had a statistically significant relationship with EB (those who did not indicate a gender had a higher EB score), while class standing had a statistically significant relationship with EK (EK increased with grade level).

\section{Response Rate}

After all invalid responses were discarded, this resulted in a total of 1,988 responses (Table 4). Survey responses were discarded if they indicated that the respondent was under the age of 18, a freshman, or a first-year graduate student from a different university than where their undergraduate degree was received. Additionally, if the respondent skipped a single question of the 15 items in the attitude, behavior or knowledge sections, the response was deemed invalid and discarded. The reasons a respondent skipped a question varies from them not knowing the answer, to computer error, or impatience, etc. Since the reasons for skipping an answer were unknown, it was 
impossible to determine if the scores should be weighted evenly or not. Therefore the responses were discarded to uphold the integrity of the fully completed surveys.

\section{Demographics of Survey Respondents}

The demographic characteristics include gender, major, class standing, and age. Each of the 4 categories had varying numbers of respondents between the Bronze- $(\mathrm{N}=133)$, Silver- $(\mathrm{N}=792)$, Gold- $(\mathrm{N}=455)$, Platinum- $(\mathrm{N}=193)$, and non-STARS-rated schools $(\mathrm{N}=415)$. For every category, besides the Gold sample, most of the respondents were females (55.6\%). Males accounted for $42.7 \%$ of respondents, while $1.7 \%$ of respondents did not indicate a gender by either leaving the question blank or choosing "prefer not to answer (PNA)."

The vast majority of respondents had majored in non-environmental related fields (96.7\%), while only $65(3.3 \%)$ respondents indicated they were majoring in an environmental-related field. Of all respondents, $3.7 \%$ neglected to disclose their major as expressed as "blank" in Table 4. For every category, the percentage of environmentalrelated majors was less than 3.6\% (Platinum), besides Bronze, which was $18 \%$.

In the Bronze, Silver, and Gold categories, graduate students responded the least, while seniors responded the most. Overall, seniors made up of $37.7 \%$ of respondents, then juniors at $27.2 \%$, graduate students at $18.8 \%$, with the least represented group being Sophomores at $16.3 \%$. Graduate respondents made up $20.8 \%$ (non-rated) or less in all categories besides Platinum, where graduate students made up the majority with $60.6 \%$ of respondents. 
For age, the majority of all groups were between the ages of 18 and 24 (71.9\%). As age increased, the number of respondents decreased. This result is unsurprising since the majority of students at the surveyed universities are within the ages of $18-24$. The Platinum category had mostly graduate student respondents, and consequently had a very high percentage $(43.5 \%)$ of respondents within the $25-35$ years age range. The next highest percentage for 25-35 years of age was Silver with $24 \%$.

Table 4

Demographic Characteristics of Survey Respondents From Each STARS Category and NonSTARS-Rated Schools

\begin{tabular}{lcccccc}
\hline Sample & Bronze & $\frac{\text { Silver }}{792}$ & $\frac{\text { Gold }}{455}$ & $\frac{\text { Platinum }}{193}$ & $\frac{\text { NR }}{415}$ & $\frac{\text { ALL }}{1,988}$ \\
Gender & 133 & & & & & \\
Male (\%) & $35(26.3)$ & $337(42.5)$ & $231(50.8)$ & $62(32.1)$ & $184(44.3)$ & $849(42.7)$ \\
Female (\%) & $95(71.4)$ & $443(56)$ & $218(47.9)$ & $122(63.2)$ & $228(55)$ & $1106(55.6)$ \\
PNA (\%) & $3(2.3)$ & $12(1.5)$ & $6(1.3)$ & $9(4.7)$ & $3(0.7)$ & $33(1.7)$ \\
Major & & & & & \\
ENV (\%) & $24(18)$ & $9(1.1)$ & $12(2.6)$ & $7(3.6)$ & $13(3.1)$ & $65(3.3)$ \\
Other (\%) & $103(77.5)$ & $760(96)$ & $433(95.2)$ & $163(84.4)$ & $391(94.2)$ & $1850(93)$ \\
Blank (\%) & $6(4.5)$ & $23(2.9)$ & $10(2.2)$ & $23(12)$ & $11(2.7)$ & $73(3.7)$ \\
Class & & & & & & \\
Soph (\%) & $39(29.3)$ & $125(15.8)$ & $70(15.4)$ & $21(10.9)$ & $69(16.6)$ & $324(16.3)$ \\
Junior (\%) & $27(20.3)$ & $235(29.7)$ & $120(26.4)$ & $14(7.3)$ & $145(34.9)$ & $541(27.2)$ \\
Senior (\%) & $59(44.4)$ & $336(42.4)$ & $199(43.7)$ & $41(21.2)$ & $115(17.7)$ & $750(37.7)$ \\
Grad (\%) & $8(6)$ & $96(12.1)$ & $66(15.5)$ & $117(60.6)$ & $86(20.8)$ & $373(18.8)$ \\
Age & & & & & & \\
$18-24(\%)$ & $116(87.2)$ & $556(70.2)$ & $340(74.7)$ & $99(51.3)$ & $318(76.6)$ & $1429(71.9)$ \\
$25-34(\%)$ & $7(5.3)$ & $190(24)$ & $91(20)$ & $84(43.5)$ & $79(19)$ & $451(22.7)$ \\
$35-44(\%)$ & $7(5.3)$ & $31(3.9)$ & $15(3.3)$ & $8(4.1)$ & $14(3.4)$ & $75(3.8)$ \\
$45-54(\%)$ & $1(0.7)$ & $9(1.1)$ & $5(1.1)$ & $2(1.1)$ & $3(0.7)$ & $20(1)$ \\
$55+(\%)$ & $2(1.5)$ & $6(0.8)$ & $4(0.9)$ & - & $1(0.3)$ & $13(0.6)$ \\
\hline
\end{tabular}

Notes. $n$ : Sample size. NR: non-STARS-rated Universities.

ALL: Bronze, Silver, Gold, Platinum, NR Categories. PNA: Prefer not to answer.

ENV: Environmental Major. Other: All non-environmental-related subjects.

Blank: Respondents that did not indicate a major. Class $=$ Class Sanding. 


\section{Central Tendency and Frequency Distribution of EL Scores}

The central tendency and frequency distribution of the EL scores were determined. Each EL score was tested separating by the attitude, behavior, and knowledge subsections. Table 5 displays the mean, median, skewness, and other statistics for each EL component. The skewness of each EL component is negative, resulting in a negative distribution with a long tail to the left as shown in Figure 3.

Table 5

Frequency Statistics for EL

\begin{tabular}{|c|c|c|c|c|}
\hline & & Attitude & Behavior & Knowledge \\
\hline \multirow[t]{2}{*}{$\mathrm{N}$} & Valid & 1988 & 1988 & 1988 \\
\hline & Missing & 0 & 0 & 0 \\
\hline Mean & & 16.05 & 12.21 & 13.35 \\
\hline Std. Error of Mean & & 0.066 & 0.066 & 0.104 \\
\hline Median & & 16.000 & 12.000 & 12.000 \\
\hline Mode & & 19.000 & 12.000 & 12.000 \\
\hline Std. Deviation & & 2.921 & 2.947 & 4.646 \\
\hline Skewness & & -1.053 & -0.247 & -.0405 \\
\hline Std. Error of Skewness & & 0.055 & 0.055 & 0.055 \\
\hline Kurtosis & & 2.013 & 0.259 & -0.313 \\
\hline Std. Error of Kurtosis & & 0.110 & 0.110 & 0.110 \\
\hline
\end{tabular}

Note. Derived from SPSS 25. 

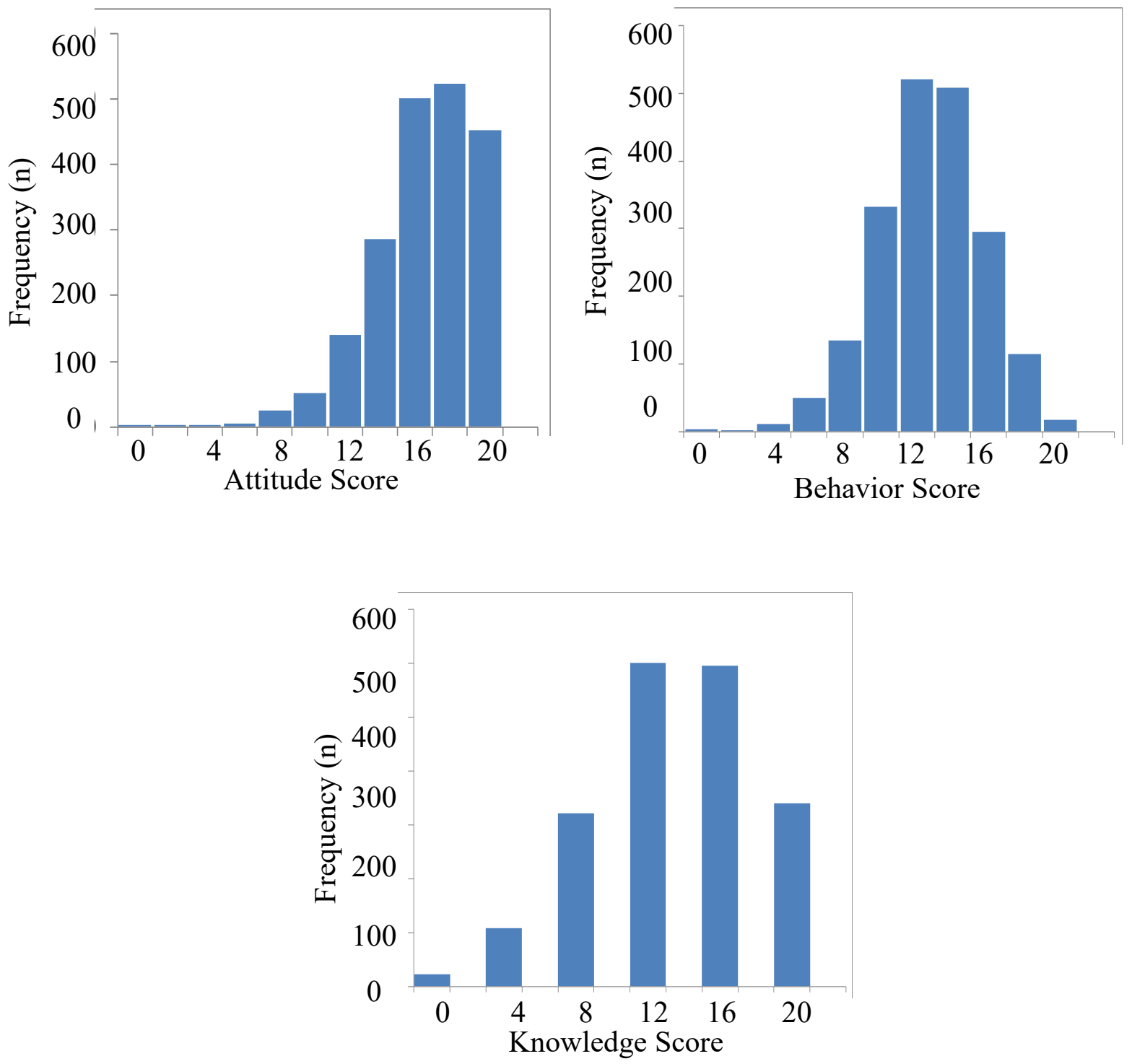

Figure 3. Frequency distributions of environmental literacy scores. Attitude $(\mathrm{M}=16.05)$, Behavior $(\mathrm{M}=12.21)$, Knowledge $(\mathrm{M}=13.35)$. $\mathrm{N}=1988$. Frequency measured by sample size. 


\section{Normality Tests on Data}

The results of both the Shapiro-Wilk and Kolmogorov-Smirnov normality tests on the dependent variable, (EL score) verified the data were non-normal (Table 6). Instead of running t-tests and ANOVA, the data required non-parametric tests to more accurately determine the relationships between variables. In place of t-tests, the Mann-Whitney U test was applied to compare any two variables in the data set. In place of ANOVA, multiple variable comparisons were examined by the Kruskal-Wallis test. Each component of EL was tested separately. Table 6 displays the normality test results for all three EL components: EA, EB, and EK. The Kolmogorov-Smirnov and the ShapiroWilk normality tests determined the data are non-normal. Table 6 shows a significance of $p<0.001$, which indicates the data are statistically different from a normal distribution. For the data to have a normal distribution, the significant value must be $p$ $>.05$.

Table 6

Normality Test Results on Environmental Score Data

\begin{tabular}{llll|lll}
\hline \multicolumn{5}{c}{ Kolmogorov-Smirnov* } & \multicolumn{4}{l}{ Shapiro-Wilk } \\
\hline & $\underline{\text { Statistic }}$ & $\underline{\mathrm{df}}$ & $\underline{\text { Sig. }}$ & $\underline{\text { Statistic }}$ & $\underline{\mathrm{df}}$ & $\underline{\mathrm{Sig}}$ \\
EA & 0.118 & 1988 & $<0.001$ & 0.926 & 1988 & $<0.001$ \\
EB & 0.080 & 1988 & $<0.001$ & 0.986 & 1988 & $<0.001$ \\
EK & 0.186 & 1988 & $<0.001$ & 0.914 & 1988 & $<0.001$ \\
\hline
\end{tabular}

Note. ${ }^{*}=$ Lilliefors Significance Correction. 


\section{Environmental Literacy between Non-STARS and STARS-Rated Schools}

Mann-Whitney U tests were used to investigate the differences in EA, EB, and EK between STARS and non-STARS-rated schools. According to the results of the MannWhitney U test (Table 7), there is no significant difference in EL between STARS-rated universities and non-STARS-rated universities. Each variable of EL (attitude, behavior, knowledge) was tested separately for differing levels of significance for each variable.

Table 7

Results Comparing EL Between STARS-Rated Schools and Non-STARS-Rated Schools

\begin{tabular}{llccccc}
\hline Sample & $\underline{\text { STARS }}$ & $\underline{N}$ & $\underline{M}$ & $\underline{S D}$ & $\underline{S E}$ & $\underline{\operatorname{Pr}>F}$ \\
& No & 415 & 15.908 & 2.861 & 0.140 & \\
& Yes & 1573 & 16.083 & 2.937 & 0.074 & \\
EB & Diff (1-2) & & -0.175 & 2.921 & 0.161 & 0.161 \\
& No & 415 & 12.210 & 3.046 & 0.149 & \\
& Yes & 1573 & 12.212 & 2.921 & 0.074 & \\
EK & Diff (1-2) & & -0.002 & 2.948 & 0.163 & 0.904 \\
& No & 415 & 12.993 & 4.924 & 0.242 & \\
& Yes & 1573 & 13.447 & 4.567 & 0.115 & \\
& Diff (1-2) & & -0.454 & 4.644 & 0.256 & 0.104
\end{tabular}

Notes. Significant at $p<.05$. EA: Environmental Attitude. EB: Environmental Behavior. EK: Environmental Knowledge. 


\section{Environmental Literacy and STARS Ranks}

A Kruskal-Wallis test was administered to investigate how student EL is impacted by STARS ranks (Bronze, Silver, Gold, and Platinum). Table 8 and Figure 4 illustrate the average scores EA, EB, and EK between the STARS ranks. According to the results from the Kruskal-Wallis test, there is no significant difference among STARS-rated schools on EA ( $p$-value $=0.266), \mathrm{EB}(\mathrm{p}$-value $=0.094)$ or EK $(\mathrm{p}$-value $=0.075)$.

Table 8

\begin{tabular}{ccccc}
\multicolumn{5}{c}{ Relationship Between STARS Ranks and Environmental Literacy } \\
\hline \multirow{4}{*}{ EA } & $\underline{\text { Rank }}$ & $\underline{M}$ & $\underline{S E}$ & $\underline{p}$ \\
& Bronze & 16.0394 & 0.2621 & 0.266 \\
& Silver & 16.2568 & 0.1067 & \\
Gold & 15.8966 & 0.1400 & \\
& Platinum & 15.6923 & 0.2272 & \\
EB & Bronze & 12.2756 & 0.2595 & 0.094 \\
& Silver & 12.2881 & 0.1056 & \\
& Gold & 11.9303 & 0.1387 & \\
& Platinum & 12.3018 & 0.2250 & \\
EK & & & & \\
& Bronze & 13.2598 & 0.4037 & 0.075 \\
& Silver & 13.4446 & 0.1643 & \\
& Gold & 13.1506 & 0.2157 & \\
& Platinum & 14.0592 & 0.3500 &
\end{tabular}

Note. Significant at $p<.05$. EA: Environmental Attitude. EB: Environmental Behavior EK: Environmental Knowledge.

Figure 4 illustrates the average score for each STARS rank, as well as non-STARSrated schools (NR) separated by attitude, behavior, and knowledge. For each EL dimension, all scores were out of 10 points. For attitude, all scores settled near 16 points with platinum scoring the lowest $(M=15.69)$ and silver scoring the highest $(M=16.26)$. For behavior, all scores settled near the 12-point marker with gold scoring the lowest (M 
$=11.85)$, and platinum schools scoring the highest $(\mathrm{M}=12.33)$. For knowledge, gold scored the lowest scored highest $(\mathrm{M}=14.06)$.

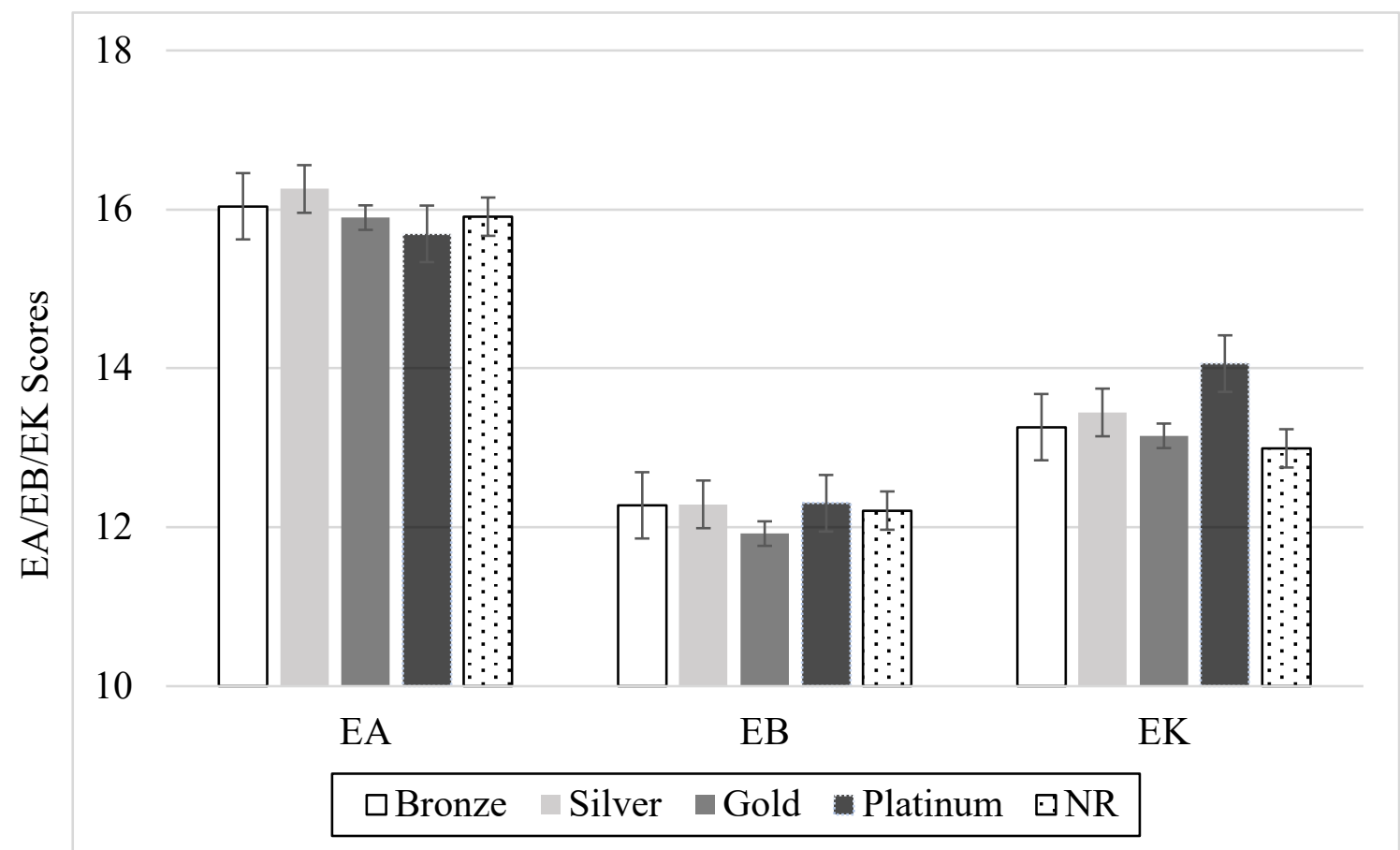

Figure 4. Comparison between STARS ranks. EL scores categorized by the individual components of EL (EA: Environmental Attitude. EB: Environmental Behavior EK: Environmental Knowledge). Bronze ( $\mathrm{N}=133)$. Silver $(\mathrm{N}=792)$. Gold $(\mathrm{N}=455)$.

Platinum $(\mathrm{N}=193)$. NR $(\mathrm{N}=415)$. Standard errors for mean scores are represented by the error bars attached to each column. No significance was found between any of the STARS ranks and environmental literacy scores since all p-values were more than 0.05 . $\mathrm{NR}=$ Non-Rated.

\section{Relationship Between Environmental Literacy Components}

The extent of the relationship between EA, EB, and EK among college students was calculated by using Spearman's analysis. Table 9 displays significant relationships between each of the EL components. A moderate relationship between attitude and behavior (correlation coefficient equals 0.47 ), a weak relationship between attitude and knowledge, and a weak relationship between behavior and knowledge (correlation coefficient equals to 0.12 and 0.10 respectively) (Table 9). 
Table 9

Correlation Between Environmental Literacy Components

\begin{tabular}{|c|c|c|c|c|}
\hline \multirow{3}{*}{ Attitude } & & Attitude & Behavior & Knowledge \\
\hline & $\begin{array}{l}\text { Pearson's } \\
\text { correlation }\end{array}$ & 1 & 0.471 & 0.116 \\
\hline & p-value & - & $<0.001$ & $<0.001$ \\
\hline \multirow[t]{2}{*}{ Behavior } & $\begin{array}{l}\text { Pearson's } \\
\text { correlation }\end{array}$ & 0.471 & 1 & 0.099 \\
\hline & p-value & $<0.001$ & - & $<0.001$ \\
\hline \multirow[t]{2}{*}{ Knowledge } & $\begin{array}{l}\text { Pearson's } \\
\text { correlation }\end{array}$ & 0.116 & 0.099 & 1 \\
\hline & p-value & $<0.001$ & $<0.001$ & - \\
\hline
\end{tabular}

Note. Spearman Correlation Coefficients, $\mathrm{N}=1988$.

\section{Summary Data of Demographic Variables}

The relationship between the EL components (attitude, behaviors, and knowledge) and the demographic variables (rank, major, class-standing, age, gender) was tested by using Spearman's analysis. Table 10 displays a significant and moderate relationship between class-standing and age (correlation coefficient equals 0.452). All other relationships between demographics are either weak or not significant. 
Table 10

Correlation Between Demographics

\begin{tabular}{|c|c|c|c|c|c|c|c|c|c|}
\hline \multirow{3}{*}{ EA } & & $\underline{\mathrm{EA}}$ & EB & EK & $\underline{\text { Rank }}$ & Major & $\underline{\text { Class }}$ & Age & Gender \\
\hline & $\mathrm{PC}$ & - & 0.471 & 0.116 & 0.003 & -0.004 & 0.009 & 0.024 & 0.031 \\
\hline & $p$ & & $<0.001$ & $<0.001$ & 0.902 & 0.861 & 0.704 & 0.280 & 0.161 \\
\hline \multirow[t]{2}{*}{ EB } & PC & & - & 0.099 & -0.005 & 0.006 & 0.016 & 0.031 & 0.054 \\
\hline & $p$ & & & $<0.001$ & 0.830 & 0.803 & 0.465 & 0.170 & 0.015 \\
\hline \multirow[t]{2}{*}{ EK } & PC & & & - & 0.036 & 0.041 & 0.057 & 0.024 & 0.022 \\
\hline & $p$ & & & & 0.107 & 0.075 & 0.11 & 0.295 & 0.317 \\
\hline \multirow[t]{2}{*}{ Rank } & PC & & & & - & -0.050 & 0.164 & 0.103 & -0.008 \\
\hline & $p$ & & & & & 0.030 & $<0.001$ & $<0.001$ & 0.716 \\
\hline \multirow[t]{2}{*}{ Major } & PC & & & & & - & -0.006 & -0.051 & 0.032 \\
\hline & $p$ & & & & & & 0.803 & 0.025 & 0.159 \\
\hline \multirow[t]{2}{*}{ Class } & $\mathrm{PC}$ & & & & & & - & 0.452 & -0.014 \\
\hline & $p$ & & & & & & & $<0.001$ & 0.539 \\
\hline \multirow[t]{2}{*}{ Age } & $\mathrm{PC}$ & & & & & & & - & -0.044 \\
\hline & $p$ & & & & & & & & 0.052 \\
\hline \multirow[t]{2}{*}{ Gender } & $\mathrm{PC}$ & & & & & & & & - \\
\hline & $p$ & & & & & & & & \\
\hline
\end{tabular}

Notes. Spearman Correlation Coefficients, $\mathrm{N}=1988$. EA: Environmental Attitude. EB: Environmental Behavior EK: Environmental Knowledge.

Class $=$ Class Standing. $\mathrm{PC}=$ Pearson's correlation. $p=$ p-value.

The demographic variables were further tested for significant differences in relation to EL scores. Each demographic variable (class-standing, age, gender, major) was tested separately depending on the number of groups per variable. According to Table 11, none of the demographic variables had significant effects on EA. Gender was found to have a significant difference for EB, while class-standing displayed a significant difference for EK. 
Table 11

Demographic Variables on Environmental Literacy

\begin{tabular}{|c|c|c|c|c|c|}
\hline & $\underline{\text { Effect }}$ & Num DF & $\underline{N}$ & $\underline{X^{2} / Z}$ & $\underline{p}$ \\
\hline \multirow{4}{*}{ EA } & Class & 3 & 1988 & $1.308^{*}$ & 0.727 \\
\hline & Age & 5 & 1985 & $7.962 *$ & 0.158 \\
\hline & Gender & 2 & 1988 & $3.127 *$ & 0.209 \\
\hline & Major & 1 & 1988 & $-0.222 * *$ & 0.825 \\
\hline \multirow[t]{4}{*}{ EB } & Class & 3 & 1988 & $3.191 *$ & 0.363 \\
\hline & Age & 5 & 1985 & $5.099 *$ & 0.404 \\
\hline & Gender & 2 & 1988 & $9.232 *$ & 0.010 \\
\hline & Major & 1 & 1988 & $-0.180 * *$ & 0.857 \\
\hline \multirow[t]{4}{*}{ EK } & Class & 3 & 1988 & $8.663^{*}$ & 0.034 \\
\hline & Age & 5 & 1985 & $1.516^{*}$ & 0.911 \\
\hline & Gender & 2 & 1988 & $1.903 *$ & 0.386 \\
\hline & Major & 1 & 1988 & $-1.710 * *$ & 0.087 \\
\hline
\end{tabular}

Notes. Significant at $p<.05$. EA: Environmental Attitude. EB: Environmental

Behavior. EK: Environmental Knowledge. $*=\mathrm{X}^{2}$. $* *=\mathrm{Z}$.

Class $=$ Class Standing. $\mathrm{X}^{2}=$ Chi-Square. $\mathrm{Z}=\mathrm{Z}$-Score.

The relationship between the STARS ranks (Bronze, Silver, Gold, Platinum, NonRated) was calculated using Spearman's analysis. According to Table 12, there are no significant correlations between any of the STARS ranks. 
Table 12

Correlation Between STARS Ranks

\begin{tabular}{|c|c|c|c|c|c|c|}
\hline \multirow{3}{*}{ NR } & & NR & Bronze & $\underline{\text { Silver }}$ & Gold & Platinum \\
\hline & $\mathrm{PC}$ & - & -0.009 & -0.011 & -0.042 & 0.228 \\
\hline & $p$ & & 0.876 & 0.346 & 0.392 & 0.106 \\
\hline \multirow[t]{2}{*}{ Bronze } & $\mathrm{PC}$ & & - & 0.068 & 0.021 & 0.073 \\
\hline & $p$ & & & 0.056 & 0.065 & 0.106 \\
\hline \multirow[t]{2}{*}{ Silver } & PC & & & - & -0.045 & 0.164 \\
\hline & $p$ & & & & 0.427 & 0.935 \\
\hline \multirow[t]{2}{*}{ Gold } & $\mathrm{PC}$ & & & & - & 0.079 \\
\hline & $p$ & & & & & 0.625 \\
\hline \multirow[t]{2}{*}{ Platinum } & $\mathrm{PC}$ & & & & & - \\
\hline & $p$ & & & & & \\
\hline
\end{tabular}

Notes. Spearman Correlation Coefficients, $\mathrm{N}=1988$. NR: Non-Rated.

$\mathrm{PC}=$ Pearson's correlation. $p=\mathrm{p}$-value.

Table 13 outlines the results of gender on each component of EL. For EB, those who preferred not to answer (PNA) scored significantly higher than both females and males. For the other EL components, EA and EK, there was no significant difference between scores across gender variables. It is important to remember that PNA only represented $1.7 \%$ of all respondents, while $55.6 \%$ of all respondents were females, and $42.7 \%$ were males. As illustrated in Table 13, when PNA was removed from the equation, so only males and females are compared with each other, there was no statistically significant difference. 
Table 13

Environmental Literacy Component Scores Results Based on Gender

\begin{tabular}{llccccc}
\hline \multirow{3}{*}{ EA } & \multicolumn{1}{c}{$\underline{\underline{n}}$} & $\underline{\underline{\mathrm{S}}}$ & $\underline{\mathrm{SD}}$ & $\underline{\mathrm{SE}}$ & $\underline{p}$ \\
& Female & 1106 & 16.11 & 2.87 & 0.09 & \\
& Male & 849 & 15.94 & 2.99 & 0.10 & $0.279^{*}$ \\
& PNA & 33 & 16.77 & 2.61 & 0.48 & $0.209^{* *}$ \\
EB & Female & - & 12.30 & 2.95 & 0.09 & \\
& Male & - & 12.05 & 2.95 & 0.10 & $0.061^{*}$ \\
& PNA & - & 13.30 & 2.52 & 0.46 & $0.010^{* *}$ \\
\multirow{2}{*}{ EK } & & & & & & \\
& Female & - & 13.40 & 4.67 & 0.14 & \\
& Male & - & 13.27 & 4.62 & 0.16 & $0.470^{*}$ \\
& PNA & - & 14.1 & 4.78 & 0.87 & $0.386^{* *}$ \\
\hline
\end{tabular}

Notes. PNA: Prefer not to answer. $*=p$-value for female $\&$ male variables.

$* *=\mathrm{p}$-value for all variables, female, male \& PNA. Significant at $p<.05$.

Table 14 displays each EL component as it relates to sophomores, juniors, seniors, and graduate students. The sample size remains the same for each component.

According to Table 14, there was no significant difference between class-standing and both, EA (p-value $=0.727)$ and EB $(p$-value $=0.363)$. Also, neither EA nor EB scores show an increase or decrease with grade level. A significant difference $(p$-value $=0.034)$ was found between EK and class-standing. With EK, scores show a steady increase as grade level increases. Sophomores scored the lowest with an average score of 13.02, next was juniors with an average score of 13.19 , then seniors with 13.29 , then graduate students with 14.01. Results from EA and EB do not follow this trend since all scores fluctuated between grade levels. 
Table 14

Environmental Literacy Component Scores Results Based on Class Standing

\begin{tabular}{llllllc}
\hline \multirow{2}{*}{ EA } & & $\underline{n}$ & $\underline{\mathrm{M}}$ & $\underline{\mathrm{SD}}$ & $\underline{\mathrm{SE}}$ & $\underline{p}$ \\
& Sophomore & 324 & 16.13 & 2.78 & 0.15 & $0.727^{*}$ \\
& Junior & 541 & 15.91 & 3.02 & 0.13 & \\
& Senior & 750 & 16.11 & 2.89 & 0.11 & \\
& Graduate & 373 & 16.04 & 2.97 & 0.15 & \\
& & & & & & \\
& SB & - & 12.30 & 2.91 & 0.16 & $0.363^{* *}$ \\
& Junior & - & 12.03 & 3.09 & 0.13 & \\
& Senior & - & 12.25 & 2.85 & 0.10 & \\
& Graduate & - & 12.31 & 2.96 & 0.15 & \\
& & & & & & \\
& Sophomore & - & 13.02 & 4.76 & 0.26 & $0.034^{* * *}$ \\
& Junior & - & 13.19 & 4.65 & 0.20 & \\
& Senior & - & 13.29 & 4.66 & 0.17 & \\
& Graduate & - & 14.01 & 4.47 & 0.23 & \\
\hline
\end{tabular}

Notes. $*=$ p-value for EA Class. $* *=$ P-value for EB Class. $* * *=$ p-value for EK Class. Significant at $p<.05$. Class $=$ Class Standing.

A Friedman two-way non-parametric test was used to test if the significant relationship between EK and class-standing was manifested across STARS groups. According to Table 15, none of the STARS ranks showed significance with class standing and EK. Silver indicated a steady increase of EK as class standing level increased. All other ranks failed to display a similar pattern. 
Table 15

Environmental Knowledge Scores on Class Standing and STARS Ranks

\begin{tabular}{llccc}
\hline \multirow{3}{*}{ Bronze } & & $\underline{\mathrm{M}}$ & $\underline{\mathrm{SD}}$ & $\underline{p}$ \\
& Sophomore & 14.50 & 4.751 & 0.454 \\
& Junior & 13.00 & 7.635 & \\
& Senior & 11.00 & 3.546 & \\
Graduate & 14.50 & 2.976 & 0.187 \\
& & & & \\
& Sophomore & 12.71 & 4.265 & \\
& Junior & 12.75 & 4.690 & \\
& Senior & 12.92 & 4.588 & \\
& Graduate & 14.25 & 4.413 & \\
& & & & \\
& Sophomore & 13.27 & 5.164 & \\
& Junior & 13.64 & 4.209 & \\
& Senior & 12.30 & 4.618 & \\
& Graduate & 12.61 & 4.224 & \\
& & & & \\
& Sophomore & 15.43 & 4.108 & \\
& Junior & 13.43 & 6.198 & \\
& Senior & 14.29 & 4.890 & \\
& Graduate & 12.86 & 3.570 & \\
\hline
\end{tabular}

Note. Significant at $p<.05$.

\section{STARS Scores Overview}

All surveyed universities had varying scores. For reasons other than the hypothesized, some schools still tested better than others. Figures 5 - 8 displays the overall score for each school, as well as the individual components: EA, EB, and EK. Soka University (Silver) had the highest average score in all three sections. As predicted, Stanford University was high on the list scoring second in all sections except for "attitude," where Stanford uncharacteristically came in tenth out of all 12 schools.

Each university had relative scores with no true outliers; each score fell into a range of only a 3-point difference of each other for most sections. EK had the highest point 
disparity (2.48), whereas EB had the lowest point disparity (1.39). For EA, 6 of the 12 schools averaged between 16 points and 16.5 points. For EB, the majority of schools (9 of 12) scored between 12 and 12.5 points. For EK, the majority of schools ( 8 of 12) scored between 13 and 13.5 points.

Figure 5 illustrates the average attitude score for each of the 12 studied universities. The school with the lowest average attitude score was (gold-rated) San Jose State $(\mathrm{M}=$ 15.44). The school with the highest average attitude score was Soka University of America $(\mathrm{M}=16.88)$, a silver-ranked school. Stanford University, the only platinumranked school studied, scored third lowest for attitude $(\mathrm{M}=15.82)$.

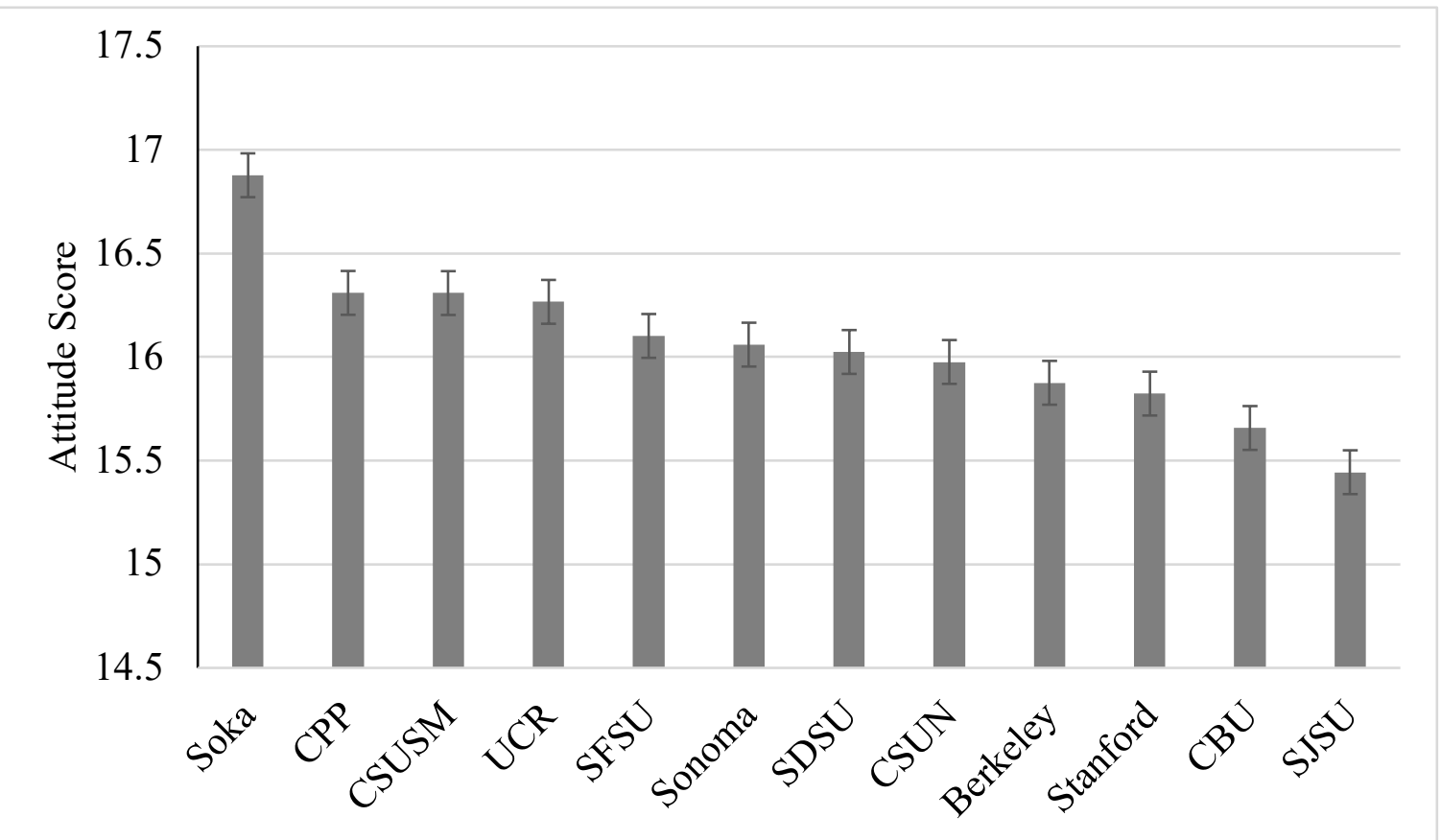

Figure 5. Average attitude score for each university. Lowest possible score: 0 . Highest possible score: 20. Standard errors for mean scores are represented by the error bars attached to each column. All schools averaged between 15 and 17 points.

Figure 6 illustrates the average behavior score for each of the 12 studied universities. Again, Soka scored the highest of all schools $(M=12.76)$, while San Jose State scored 
the lowest $(M=11.36)$. Again, Cal Baptist University (a non-STARS-rated school) had the second lowest score $(M=11.84)$. Stanford University $(M=12.47)$ scored second to Soka University of America. For behavior, there are no gold-ranked schools in the top 5 highest scoring schools. The highest gold-ranked school is UC Riverside placing in sixth. Also, each of the non-STARS-rated schools were of the 5 lowest scoring schools.

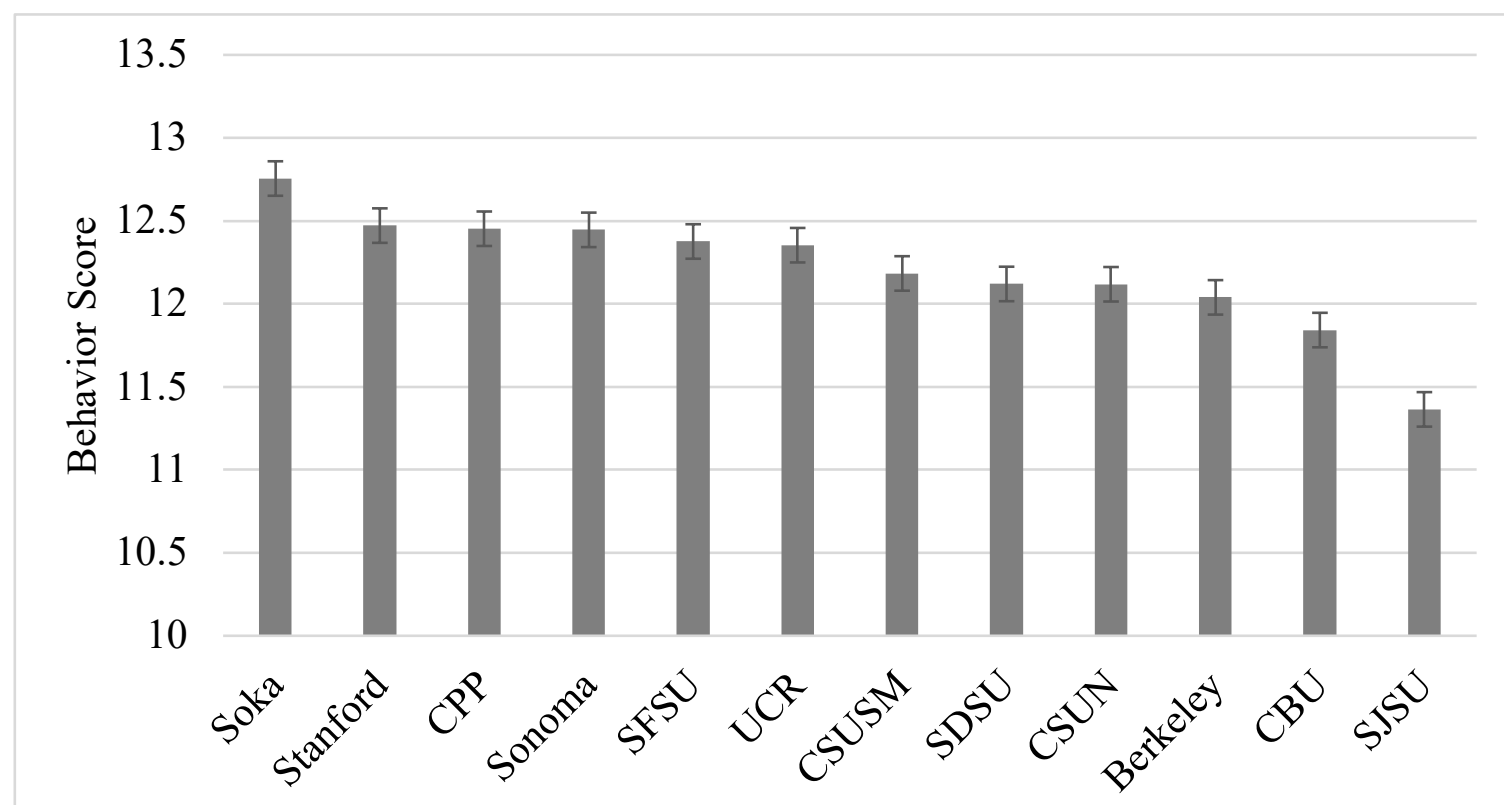

Figure 6. Average behavior score for each university. Lowest possible score: 0 . Highest possible score: 20. Standard errors for mean scores are represented by the error bars attached to each column. All schools averaged between 11 and 13 points.

Figure 7 illustrates the average knowledge score for each of the 12 studied universities. Again, Soka University of America $(M=15.27)$ towers over each school. Similar to the attitude scores, Stanford University $(\mathrm{M}=17.07)$ scored second highest, $\mathrm{Cal}$ Poly Pomona $(\mathrm{M}=13.57)$ scored third highest and Sonoma University $(\mathrm{M}=13.47)$ scored fourth highest. This time, San Jose State $(M=13.28)$ had the fifth highest score, while UC Berkeley scored the lowest $(\mathrm{M}=12.79)$. Within knowledge, San Jose State 
was the highest scoring gold-rated school at fifth place. All non-rated schools were in the lowest six schools, while 3 of the 4 silver-ranked schools were within the top six.

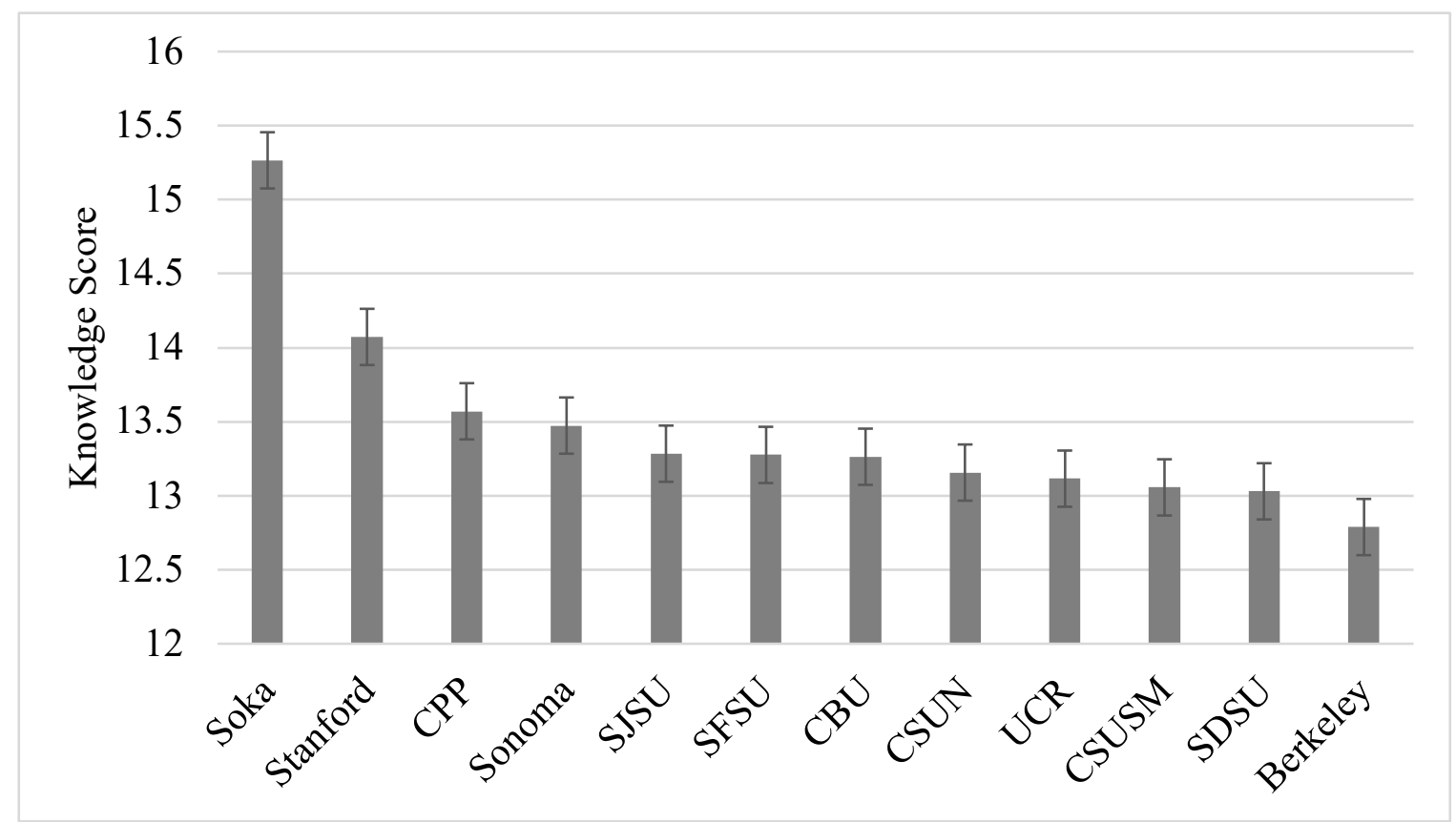

Figure 7. Average knowledge score for Each University. Lowest possible score: 0. Highest possible score: 20. Standard errors for mean scores are represented by the error bars attached to each column. All schools averaged between 12.5 and 15.5 points.

Figure 8 illustrates the overall score for each of the 12 studied universities. The overall score includes the sum of each EL dimension: attitude, behavior, and knowledge. Soka University of America $(\mathrm{M}=44.90)$ is in the lead scoring 2.53 points higher than the second highest school, Stanford University. All other schools scored between 42.37 points (Stanford) and 40.09 points (San Jose State), with the point disparity being 2.28 points. With Soka University included, the point disparity from highest to lowest is 4.81 points. Overall, no gold and non-rated schools are found in the top five highest scoring schools. 


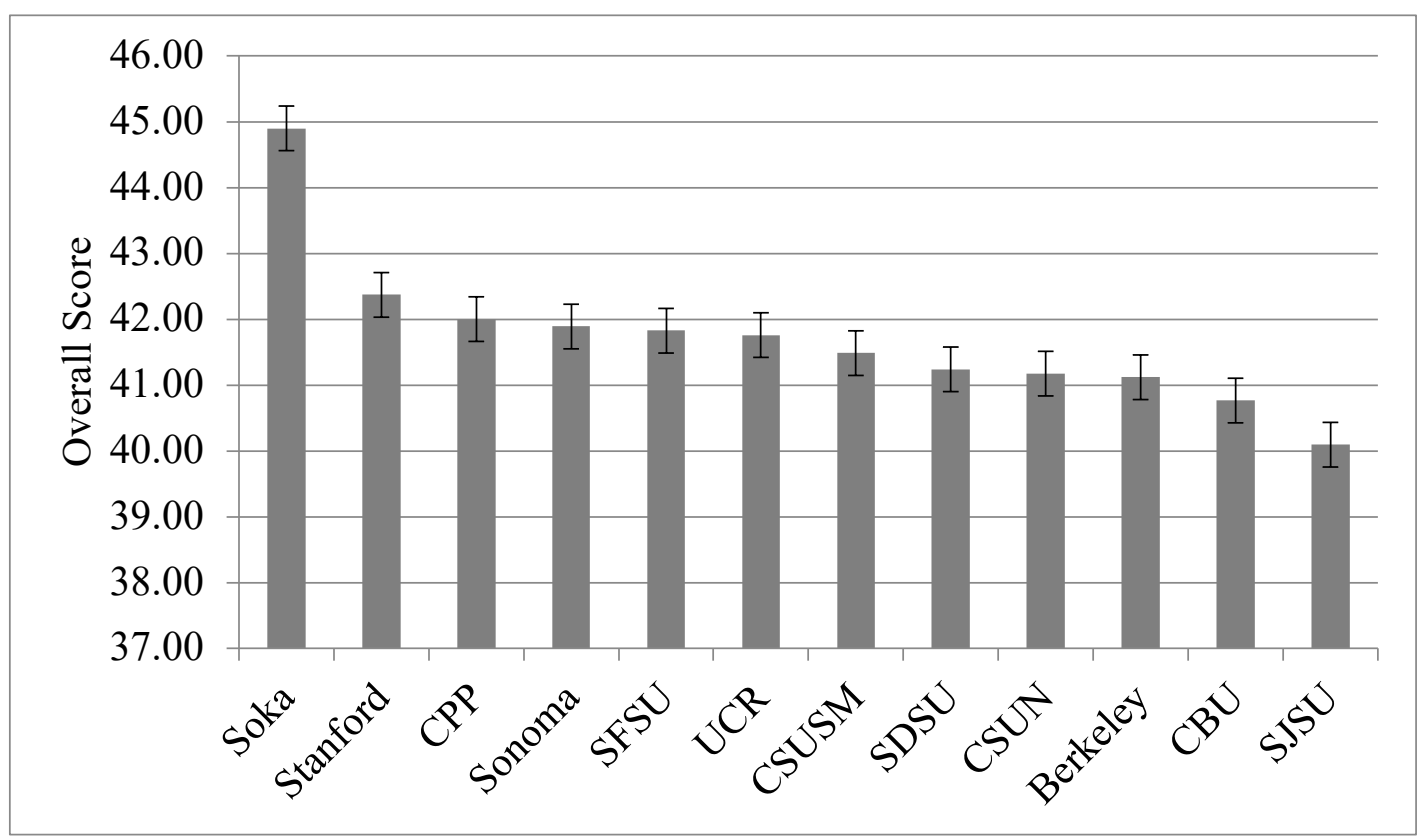

Figure 8. Average overall score for each university. Lowest possible score: 0 . Highest possible score: 60 . Standard errors for mean scores are represented by the error bars attached to each column. All schools averaged between 40 and 45 points. 


\section{Discussion}

The primary purpose of this study was to determine if a university's sustainability score impacts student EL. Does the presence of sustainability features or campaigns affect how a student comprehends environmental issues? Specifically, can a university's STARS report, or lack thereof, determine the level of student EL? A total of 1,988 students from 12 different universities throughout the state of California were surveyed to find the answer to this question. Of the 12 total schools, one was rated Platinum, three were rated Gold, four were rated Silver, one was rated Bronze, and three were not rated.

There was no significant difference was found between STARS and non-STARSrated schools. These results imply that whether or not a school elects to be rated by the STARS report, students will still exhibit a near equal level of EL. Even though there was no significance between components, the average score for STARS-rated schools was higher for each EL component than the average score for non-STARS-rated schools. STARS-rated schools performed better in EA by 0.17 points, in EB by only 0.002 points, and in EK by 0.045 points. Although this is true, the tests suggest the presence of a STARS report does not cause this occurrence.

That fact that no statistical difference was found between STARS-rated schools and non-STARS-rated schools is most likely because the lack of a STARS rank does not automatically translate to a poor Sustainability score. Being a non-STARS-rated school only indicates the school has not yet participated in the program. Therefore, a university's true STARS rank is not revealed until the school participates in the STARS report. For instance, a non-rated university might have a higher or equal ratio of 
sustainability courses per overall courses compared with a STARS-rated school. Moreover, a non-rated university might have more or a near equal amount of conservation tactics and sustainable characteristics then that of a school that has already participated in the STARS program. Since this might have been the case with the nonrated schools in this study (UC Berkeley, Cal Baptist, and San Diego State), survey scores from these schools versus survey scores from STARS-rated schools are not statistically different from each other.

There was no significant relationship was found between the four STARS ranks (Platinum, Gold, Silver, Bronze). This result signifies that sustainability features or other environmental aspects on campus indicated in the STARS report do not impact student EL between ranks. Although this is true, some EL scores reflect the hypothesized relationship yet fluctuate in consistency. For instance, the Platinum rank received the highest scores in two of the EL components, EB, and EK, yet received the lowest score in EA. The Bronze rank performed the best in regard to EA, while the Gold rank performed the poorest in both EB and EK. This phenomenon is most likely due to STARS points being allocated for sustainability efforts that do not explicitly impact student education or experiences. More than half of STARS criteria relate to efforts of the administration, facility developments, and operations. For example, a school can be awarded points on the basis of water and energy conservation, the percentage of employees who receive sustainable compensation or administrative sustainable purchases. Although these criteria, if perused, are indicative of a sustainable campus, these types of characteristics often go unbeknownst among students and, therefore, would have no impact on student 
EL. The only chance for characteristics like these to actually have an impact on student education is to incorporate signage or informational placards of said achievements throughout the campus for students to view and learn from. Two studies have found signage to significantly impact behavior on college campuses. Ford and Torok (2010) found that displaying health-related motivational signage significantly increased stair use by $18.6 \%$ on a college campus. Nettle, Nott, and Bateson (2012) found that placing signs over bicycle racks that read "Cycle Thieves, We Are Watching You" decreased bike theft by $62 \%$ within those particular bike racks. These studies indicate that students are prone to absorb messages on signs and have the ability to conceptualize behavioral changes based on the provided information.

Although each EL component had a significant relationship, attitude and knowledge had a weak relationship as well as behavior and knowledge. On the other hand, attitude and behavior proved to be moderately correlated. These results both echo and contradict correlation studies in the past (Kaiser et al., 1999; Hines et al., 1989). Findings by Kaiser et al. (1999) have attributed both knowledge and attitude, as being connected to behavior. Following suit, Hines et al. (1989) created a model of responsible EB by performing a meta-analysis on separate studies involving the influential factors for behavioral change. They combined "attitude" with two other attitudinal variables to create "personality factors." "Knowledge" was combined with two other cognitive variables, triangulating into "intentions," which Hines et al. (1989) then argue is the primary predictor of environmental behaviors. 
Demographic variables (class standing, age, gender, major) were all tested separately for significance in relation to EL scores. Gender and class standing were the only variables that were found to influence certain EL components. Gender had a significant relationship with EB, while class standing had a significant relationship with EK.

Regarding gender, females scored 0.25 points higher than males for EB, but no statistical difference was found between means $(\mathrm{p}$-value $=0.064)$. There was a statistically significant difference, however, when all variables for gender are taken into account, including those who preferred not to indicate a gender. Those who preferred not to answer (PNA) scored 1 point higher than females and 1.25 points higher than males. Although the point difference between PNA and those who did indicate a gender was significantly different for the other two options, the small sample size for PNA should be considered.

The relationship between PNA and EB should be explored further. There has been little research directly connecting gender-transcendence and environmental thought. Although, many researchers have found that individuals who have values of "selftranscendence," rather than "self-enhancement," have been positively correlated with EB (Fukukawa et al., 2007; Karp, 1996; Lindeman and Verkasalo, 2005; Schwartz, 1992; Schwartz and Rubel, 2005). A connection between gender-transcendence (or genderneutral-mindedness) and environmentalism have yet to be explicitly studied.

Regarding class standing, EK showed a significant and positive relationship with student grade level. While class standing was a significant predictor of EK, the other components (EA and EB) did not show a significant difference with fluctuating scores 
between all classes. Although for EK, the level of EK increased as grade level increased. The average score for EK increased from sophomore to graduate students with sophomores scoring the lowest and graduate students scoring the highest. Knowledge, as a whole, should increase with grade level as students enroll in more courses and are exposed to more assignments, experiences, and concepts. The significance between class standing and EK was explored further by testing within STARS ranks: Bronze, Silver, Gold, and Platinum. Although the Silver rank showed similar patterns of EK increasing as grade level increases, all results for each STARS rank did not display a statistically significant relationship.

According to Figures 5-8, Soka University of America had the highest EL score in all three categories. Soka, being a recent Bronze-rated school - now Silver - still scored higher than each school in its same category, as well as each school with higher ranks. What can be said about Soka's impressive streak? What type of strategies, operations, or structures has Soka implemented on its campus that could have contributed to its students' EL? Only speculations can be deduced from a review and comparison of STARS points across schools.

First, how can a Silver rank school (Soka) compare with a Platinum-ranked school (Stanford)? Stanford received 88 points in its last STARS report, and Soka received 50.71 points. Stanford scored higher than Soka in every STARS subcategory except one - "academic courses" within the Curriculum category, while Soka received all points possible (14/14) and Stanford received 12 out of the 14 points. In this category, schools are granted points based on the percentage of sustainability courses offered and the 
number of academic departments that offer at least one sustainability-related course. The point difference in this section between Soka and Stanford was due to Soka's higher percentage of sustainability-focused courses and departments. Out of all courses offered at Soka, $20.9 \%$ are sustainability courses, while only $18.76 \%$ of Stanford's courses are sustainability-related. Following suit, 100\% of Soka's academic departments offer at least one sustainability course, compared with Stanford's $70.45 \%$. According to these statistics, James Gibson (1979) can argue that Soka affords its students more exposure to environmental teachings. James Gibson's (1979) affordance theory directly suggests that students' behavior and knowledge are limited to their environment. Therefore, more environmental classes should afford students the chance to consume and retain more environmental concepts and ultimately increase student EL.

While Soka received more points than Stanford in the "Academics Courses" section, it should not go unmentioned that Soka only has four academic departments, being that it is a liberal arts university. Out of Stanford's 88 academic departments, 62 offer at least one sustainability-related course. This information may imply that a sustainabilityfocused curriculum is a key to an environmentally literate student population. Although, according to STARS, Soka (20.9\%) and Stanford (18.76\%) do not have the highest percentages of sustainability-related courses of the university sample despite having the two highest EL scores. Instead, Cal State Northridge (CSUN) has the highest sustainability-related course per course ratio (23.28\%).

Similar to Stanford, CSUN scored higher than Soka in each category and subcategories within the STARS report except in one subcategory. CSUN received half 
of the possible points in the "Undergraduate Program" section, while Soka received full points. This section allows universities to showcase at least one sustainability-focused major, degree program, or "interdisciplinary academic program that concentrates on sustainability as an integrated concept." Both Soka and Stanford (and many other schools in the University sample) have an academic program (major) solely focused on Environmental Science, whereas CSUN does not. Instead, CSUN offers a minor in Sustainability. The lack of an Environmental Science major could have contributed to CSUN's low overall EL score, despite having the highest sustainability-related course ratio. Again, Soka affords its students the chance to major in Environmental Science. This affordance (James Gibson, 1979) of an entire department dedicated to environmental thought may have attributed to Soka's high EL score. 


\section{Conclusions}

Our planet is on the verge of irreversible environmental damage. Most of this damage is a result of human activity rapidly increasing the temperature of Earth's climate. We have destroyed natural habitats through deforestation, and have been the sole contributor of all plastic, air, ground, and water pollution. Many individuals are unaware of how their behaviors have had such an impact on Earth's climate. Environmental educators have the responsibility of compelling the current and next generations to live sustainably. Living in such a way that promotes healthy ecosystems is not only beneficial to other species, but also our own well-being. It is essential that all citizens of Earth, not just the few considered "environmentalists," are completely environmentally literate. An environmentally literate individual has the ability to evaluate the health of ecosystems and take appropriate action to mitigate or restore environmental problems (Roth, 1992). Since individuals have collectively caused Earth's destruction, we have the responsibility to solve the problems we have created.

Although universities act as epicenters for creating and implementing innovative environmental protection practices, more improvement is needed in developing student EL. Despite universities' efforts to make their campuses increasingly sustainable, no relationship was found between EL and STARS ranks. STARS ranking does not impact EL of a school's student body given the fact that EL remains level among schools of all ranks (including non-rated schools). There is still room for improvement even in schools that have higher STARS ranking than others. Platinum- and Gold-rated schools, especially, need to understand that the EL of their student population does not depend on 
the amount of points they receive through their STARS report. While it is a considerable achievement for many universities to reduce carbon emissions and conserve resources to combat climate change, more should be done to ensure students have a proper understanding of sustainability as a concept.

As previously stated, it is apparent that schools with a higher concentration of sustainability courses within the overall curriculum show signs of increased EL. Therefore, in order to increase student EL, every department should include at least one course on sustainability or relating to sustainability whether or not that department or major is traditionally science-based. Most, if not all, majors are connected to or impacted by environmental issues in some way. The failure of incorporating sustainability or environmental science in some majors is a great disservice to the students and the planet. Furthermore, all universities should offer a Sustainability or Environmental Science Department. Offering a department focused solely on sustainability allows students to not only pursue sustainability as a long-term career but also prepares students to solve the existing environmental issues of today in their given fields.

By comparing universities within the study sample, this project can serve as a guide for determining which attributes and management practices most positively affect rates of EL in students. Through careful consideration of the survey results and STARS points, this project should allow universities the opportunity to effectively choose where to focus when implementing new strategic ways to increase the level of EL among all students. By doing so, universities will be able to guarantee the emergence of an environmentally literate society, with the capabilities to strengthen Earth's vitality. 


\section{Recommendations}

The findings in this study indicate that STARS scores do not determine how well students understand environmental concepts or engage in EB. The STARS report remains one of the most insightful and meaningful observations of environmental prospects within higher education. A more in-depth comparison between EL and STARS criteria is recommended for future projects. The following action plans are recommended for future research as well as for higher education environmental educators and managers.

Future Research:

- Condense survey items to ten questions or less. More than 500 surveys were discarded due to incompletion. A sizable portion of discarded surveys had only ten questions answered. In order to avoid noncompletion and survey fatigue, fewer questions should be used.

- Explore alternative survey instruments. Some answer items on the WES EK section were not as clear or straightforward as other surveys. For instance, one question, in particular, had respondents' answers split 50/50 on two answers. Using multiple EL survey instruments instead of one will allow future researchers to choose the best elements from existing survey instruments.

- Further research is needed to explore the relationship between gender (specifically PNA) and EB. 
Higher Education Environmental Educators and Managers:

- Universities should incorporate sustainability into more courses within the academic curriculum. Thesis courses should either be sustainability courses or include sustainability per STARS measurements, standards, and terms.

- Universities should prioritize increasing the number of academic departments that offer at least one sustainability course and/or that includes sustainability.

- Academic program managers should make it a priority to offer at least one sustainability-focused major (and minor), degree program, or interdisciplinary academic program that concentrates on sustainability as an integrated concept.

- Universities should display informational signage around campus to showcase the behind-the-scenes sustainable achievements of the university. 


\section{References}

AASHE. (n.d.-a). Associations for the Advancement of Sustainability in Higher Education. (n.d.-a) History of AASHE. Retrieved from: https://www.aashe.org/about-us/aashe-history/

AASHE. (n.d.-b). Associations for the Advancement of Sustainability in Higher Education. HEASC. Retrieved from: https://www.aashe.org/partners/heasc/

Ajzen, I. (1991). The theory of planned behavior. Journal of Organizational Behavior and Human Decision Processes, 50(2), 179-211.

Alshuwaikhat, \& Abubakar. (2008). An integrated approach to achieving campus sustainability: Assessment of the current campus environmental management practices. Journal of Cleaner Production,16(16), 1777-1785.

Althen, Aline. (2015). Elon University: 25 LEED Buildings and Counting. U.S. Green Building Council, Retrieved February 1, 2019 from www.usgbc.org/articles/elonuniversity-25-leed-buildings-and-counting.

Banerjee, B., \& McKeage, K. (1994). How green is my value: exploring the relationship between environmentalism and materialism. ACR North American Advances, 21, 147152.

Bloom, B. S. (Ed.), Engelhart, M. D., Furst, E. J., Hill, W. H., \& Krathwohl, D. R. (1956). Taxonomy of educational objectives. The classification of educational Handbook 1: domain. New York:David McKay.

Bogan, M. B. \& Kromrey, J. D. (1996) Measuring environmental literacy of high school students. Florida Journal of Education Research, 36(1), 1-21.

Champeau, R. (1983). Development of a perceived environmental control measure. (Doctoral dissertation, Michigan State University, 1982). Dissertation Abstracts International, 45 (10), 2974-A.

Champeau, R. (1997). Environmental education in Wisconsin: Are we walking the talk. Stevens Point, WI: Wisconsin Center for Environmental Education. Retrieved from: https://www.uwsp.edu/cnr-ap/wcee/Documents/AreWeWalkingtheTalk.pdf

Cole, L., \& Wright, T. (2003). Assessing sustainability on Canadian University campuses: development of a campus sustainability assessment framework. (Unpublished master's thesis) Royal Roads University, Victoria, BC. 
Dewey, J. (1938). Experience and education. (Kappa Delta Pi lecture series). New York: Macmillan.

Dewey, J., \& Bentley, A. (1946). Interaction and transaction. The Journal of Philosophy, 43(19), 505-517.

Dunlap, R. E., \& VanLiere, K. D. (1978). The "new environmental paradigm": A proposed measuring instrument and preliminary results. Journal of Environmental Education, 2 (4), pp. 10-19.

Dunlap, R. E., Van Liere, K. D., Mertig, A. G., \& Jones, R. E. (2000). New trends in measuring environmental attitudes: measuring endorsement of the new ecological paradigm: a revised NEP scale. Journal of Social Issues, 56(3), 425-442.

Ehlers, E., \& Krafft, T. (2006). Earth System Science in the Anthropocene. In: Springer, Berlin, Heidelberg.

Elder, Jim. (2007). Campaign For Environmental Literacy. About. Retrieved March 23, 2019 from http://www.fundee.org/about/contact.htm

Engleson, D.C., Benson, J., Chandler, A, \& Bethke E. (1985). A guide to curriculum planning in environmental education. Madison, WI: Wisconsin Department of Public Instruction.

Fah, L. Y., \& Sirisena, A. (2014). Relationships between the knowledge, attitudes, and behavior dimensions of environmental literacy: a structural equation modeling approach using smartpls. Journal for Educational Thinkers, 5, 119-144.

Federal Interagency Committee on Education Subcommittee on Environmental Education. (1978) Toward an action plan: A report on the Tbilisi conference on education. Washington, DC: U.S. Department of Health, Education, and Welfare. (ERIC Document Reproduction Service No. ED 155 063) Retrieved from https://files.eric.ed.gov/fulltext/ED155063.pdf

Fishbein, Martin and Leek, Ajzen. (1975). Belief, Attitude, Intention, and Behavior: An Introduction to Theory and Research. Philosophy Rhetoric, 10 (2), 130-32.

Fisher, A. (2002). Radical ecopsychology: Psychology in the service of life. New York: State University of New York Press.

Fjørtoft, I. (2001). The natural environment as a playground for children: The impact of outdoor play activities in pre-primary school children. Early Childhood Education Journal, 29(2), 111-117. 
Fleischer, Deborah. (2017) Green Impact, University of California San Francisco, Office of Sustainability, Retrieved from: http://sustainability.ucsf.edu/1.662

Ford, M., \& Torok, D. (2008). Motivational Signage Increases Physical Activity on a College Campus. Journal of American College Health, 57(2), 242-244.

Fukukawa, K., Shafer, W.E. \& Lee, G.M. (2007) Values and attitudes toward social and environmental accountability: a study of MBA students. Journal of Business Ethics, 71, 381-394.

Green, M., \& Sandiford, Janice. (1997). The Effect of Participation in a "Greening the BCC Curriculum." Workshop Series on the Environmental Literacy of a Community College Faculty, (Doctoral Dissertation) ProQuest Dissertations and Theses. Received from https://digitalcommons.fiu.edu/dissertations/AAI9732017

Greenwald, A., McGhee, D., Schwartz, J., \& Kruglanski, Arie W. (1998). Measuring Individual Differences in Implicit Cognition: The Implicit Association Test. Journal of Personality and Social Psychology, 74(6), 1464-1480.

Gibson, J. J. (1979). The ecological approach to visual perception. Boston: Houghton Mifflin.

Goudie, A. S. (2013). The Human impact on the natural environment: past, present, and future. John Wiley \& Sons.

Heerwagen, J. (2009). Biophilia, health, and well-being. Restorative commons: creating health and well-being through urban landscapes, USDA Forest Service, Pennsylvania, 39-57.

Hines, J. M., Hungerford, H R. \& Tomera, A. N. (1987): Analysis and Synthesis of Research on Responsible Environmental Behavior: A Meta-Analysis. The Journal of Environmental Education, 18:2, 1-8

Horvat, R. E., \& Voelker, A.M. (1976). Using a Likert scale to measure "environmental responsibility". Journal of Environmental Education (1), 36-47.

Housing \& Dining Services, University of Colorado Boulder. (2017). Sustainability. Retrieved March 16, 2019 from: https://iving.colorado.edu/sustainability

Hsu, S., \& Roth, R. (1998). An Assessment of Environmental Literacy and Analysis of Predictors of Responsible Environmental Behaviour Held by Secondary Teachers in the Hualien Area of Taiwan. Environmental Education Research, 4(3), 229-249. 
Hungerford, H. R., and Peyton, R. B. (1976). Teaching Environmental Education. Portland, ME: J. Weston Walch.

Hungerford, H. R., \& Tomera, A. N. (1977). Science in the Elementary School: A Worktext. Champaign, Illinois: Stipes Pub Llc.

Hungerford, H., Peyton, R., \& Wilke, R. (1980). Goals for curriculum development in environmental education. Journal of Environmental Education, 11 (3), 42-47.

Iozzi, L. A. (1978). The environmental issues test (EIT): A new assessment instrument for environmental education. In C. D. Davis and A. Sacks (Eds.), Current Issues IV: The Yearbook of Environmental Education and Environmental Studies (pp. 200-206). Columbus, OH: Eric/Smeac.

Iozzi L., Laveault D., and Marcinkowski T. (1990). Assessment of Learning Outcomes in Environmental Education. Paris: United Nations Educational, Scientific, and Cultural Organization.

Kaiser, EG. (1998). A general measure of ecological behavior. Journal of Applied Social Psychology, 28, 395-422

Kaiser, F. G., Wolfing, S., and Fuhrer, U. (1999). Environmental Attitude and Ecological Behavior. Journal of Environmental Psychology 19: 1-1

Karp, D. G. (1996). Values and their effect on pro-environmental behavior. Environment and Behavior, 28, 111-133.

Kibert, N. C. (2000). An analysis of the correlations between the attitude, behavior, and knowledge components of environmental literacy in undergraduate university students (Master's thesis, University of Florida). Retrieved from http://citeseerx.ist.psu.edu/viewdoc/download?doi=10.1.1.26.2627\&rep=rep1\&type= pdf

Kolb, D. (1984). Experiential learning: Experience as the source of learning and development. Englewood Cliffs, N.J.: Prentice-Hall.

Leopold A. (1953). A Sand County Almanac. New York: Oxford University Press.

Lewin, Kurt. (1939). Field Theory and Experiment in Social Psychology: Concepts and Methods. American Journal of Sociology, 44, no. 6 868-896.

Lindeman, M. \& Verkasalo, M. (2005) Measuring values with the short Schwartz's value survey. Journal of Personality Assessment, 85, 170- 178. 
Maloney, M. P., \& Ward, M. P. (1973). Ecology: Let's hear from the people. An objective scale for the measurement of ecological attitudes and knowledge. American Psychologist, 28, 583-586.

Maloney, M., Ward, M., \& Braucht, G. (1975). A revised scale for the measurement of ecological attitudes and knowledge. American Psychologist, 30: 787-790.

Mayer, F. S., \& Frantz, C. M. (2004). The connectedness to nature scale: A measure of individuals' feeling in community with nature. Journal of Environmental Psychology, 24(4), 503-515.

McClaren, M. (1989). Environmental literacy: A critical element of a liberal education for the 21st century. Manitoba: Education Manitoba.

Meinhold, J. L., \& Malkus, A. J. (2005). Adolescent environmental behaviors: Can knowledge, attitudes, and self-efficacy make a difference? Environment and behavior, 37(4), 511-532.

National Environmental Education and Training Foundation (1998). National Report Card on Environmental Knowledge, Attitudes and Behaviors: 7th Annual Survey of Adult Americans. Washington, DC: National Environmental Education and Training Foundation

Nettle D, Nott K, Bateson M (2012) 'Cycle Thieves, We Are Watching You’: Impact of a Simple Signage Intervention against Bicycle Theft. Plos One, 7(12): e51738. Retrieved from https://doi.org/10.1371/journal.pone.0051738

O'Brien, S. R. M. (2007). Indications of environmental literacy: using a new survey instrument to measure awareness, knowledge, and attitudes of university-aged students. (Master's thesis, Iowa State University). Retrieved from: https://lib.dr.iastate.edu/cgi/viewcontent.cgi?article=16054\&context=rtd

Orr D. (1994). Earth in Mind. Washington (DC): Island Press. 1997. Architecture as Pedagogy II. Conservation Biology, 11: 597-60.

Pe'er, S., Goldman, D., \& Yavetz, B. (2007). Environmental literacy in teacher training: attitudes, knowledge, and environmental behavior of beginning students. The Journal of Environmental Education, 39(1), 45-59.

Peri, Phyllis. (1996). The development of an instrument to assess environmental literacy of eleventh grade students in Wisconsin (Unpublished Master's thesis). University of Wisconsin, Stevens Point. 
Phillips, Trevor Joseph; Tibbels, Kirkland; Patterson, John (2013). Transactionalism: an historical and interpretive study. Ojai, California: Influence Ecology.

Pierce M. (1992). Campus energy management programs. In Eagan DJ, Orr D, eds. The Campus and Environmental Responsibility. San Francisco: Jossey-Bass.

Poff, D. (2019). Edited by Daniel T. L. Shek and Robert M. Hollister: Book Review of "University Social Responsibility and Quality of Life: A Global Survey of Concepts and Experiences". Quality of Life in Asia Series, Volume 8. Applied Research in Quality of Life, 14(2), 563-565.

Quale, A. (1992). The development of instruments to assess environmental literacy of fifth grade students in Wisconsin. (Unpublished Master's thesis). University of Wisconsin, Stevens Point.

Ramsey, J., \& Hungerford, H. R. (1989). The effects of issue investigation and action training on environmental behavior in seventh grade students. Journal of Environmental Education, 20 (4), 29-34.

Rillo, T. J. (1974). Basic guidelines for environmental education. Journal of Environmentl Education, 6(1), 52-55.

Rokeach, M. (1968). Beliefs, attitudes, and values. San Francisco: Jossey-Bass.

Roszak, T. (1995). Where Psyche Meet Gaia. In T. Roszak, M. E. Gomes, \& A. D. Kanner (Eds.), Ecopsychology: Restoring the Earth, Healing the Mind. San Francisco: Sierra Club Books.

Roth, Charles E. (1968). On the road to conservation. Massachusetts Audubon, June p. $38-41$.

Roth, C. (1992) Environmental literacy: Its roots, evolution and directions in the 1990s, Columbus, OH: ERIC Clearinghouse for Science, Mathematics, and Environmental Education.

Rowe, Debra. (2002). Environmental literacy and sustainability as core requirements: success stories and models. Teaching sustainability at universities, 79-103.

Sadler, E., \& Given, L. (2007). Affordance theory: A framework for graduate students' information behavior. Journal of Documentation, 63(1), 115-141.

Schaeffer, Eric V. (2000). Universities, Colleges Not Receiving Top Marks for Environmental Compliance. Enforcement Alert 1-4. EPA Retrieved from: https://www.epa.gov/oeca/ore/enfalert 
Schultz, P. W., Shriver, C., Tabanico, J., \& Khazian, A. (2004). Implicit connections with nature. Journal of Environmental Psychology, 24, 31-42.

Schultz, P. W. (2001). The Structure Of Environmental Concern: Concern For Self, Other People, And The Biosphere. Journal of Environmental Psychology, 21(4), 327-339.

Schwartz, S.H. (1992). Universals in the content and structure of values: theoretical advances and empirical tests in 20 countries. Advances in Experimental Social Psychology, 25, 1-65.

Schwartz, S.H. \& Rubel, T. (2005). Sex differences in value priorities: cross-cultural and multi-method studies. Journal of Personality and Social Psychology, 89, 10101028.

Sia, A. (1985). An investigation of selected predictors of overt responsible environmental behavior. (Doctoral dissertation, Southern Illinois University at Carbondale). Dissertation Abstracts International, 46 (3), 667-A.

Tbilisi Intergovernmental Conference on Environmental Education. (1978). Toward an action plan: A report on the Tbilisi Conference on Environmental Education. Washington DC: U.S. Government Printing Office, Stock No. 017-080-01838-1.

Thorpe, M., Edwards, R., \& Hanson, A. (1993). Culture and processes of adult learning: $A$ reader (Learning through life. London; New York: Routledge in association with the Open University.

Todt, D. (1995). An Investigation of the Environmental Literacy of Teachers in Southcentral Ohio Using the Wisconsin Environmental Literacy Survey, Concept Mapping and Interviews, (Doctoral dissertation) Available from ProQuest Dissertations and Theses. Retrieved from https:/etd.ohiolink.edu/

Transportation Solutions, Associated Students, San Jose State University. (2017). Eco Pass Clipper Overview. Retrieved from http://www.sjsu.edu/as/departments/ts/smartpass/index.html

UC Davis Arboretum, University California of Davis. (2018). About us. Retrieved from http://arboretum.ucdavis.edu/about_us.aspx

Uhl, C., \& Anderson, A. (2001). Green Destiny: Universities Leading the Way to a Sustainable Future. BioScience, 51(1), 36-42 
Velazquez, L., Munguia, N., Platt, A., \& Taddei, J. (2006). Sustainable university: what can be the matter? Journal of Cleaner Production, 14(9-11), 810-819.

Wackernagel, M., \& Rees, W. (1996). Our Ecological Footprint. Gabriola Island: New Society Publishers. Future. BioScience, 51(1), 36-42.

Wang, J., \& Chameides, B. (2007). Are Humans Responsible for Global Warming? A review of the facts. Environmental Defense, New York. Received from http://www.Edf.org/home.cfm

Wang, Y., Shi, H., Sun, M., Huisingh, D., Hansson, L., \& Wang, R. (2013). Moving towards an ecologically sound society? Starting from green universities and environmental higher education. Journal of Cleaner Production, 61, 1-5.

Yumusak, Ahmet; Sargin, Seyid Ahmet; Baltaci, Furkan, \& Kelani, Raphael R. (2016). Science and Mathematics Teacher Candidates' Environmental Knowledge, Awareness, Behavior and Attitudes. International Journal of Environmental and Science Education, 11(6), 1337-1346. 


\section{Appendix A: Recruitment email and consent notice}

\section{Subject line: Graduate Thesis Environmental Literacy Survey Project}

Body: Hello, I am AnaLisa Campos and I am a graduate student in the Department of Environmental Science at San Jose State University. As part of my Master's Thesis, I am conducting research on how a school's Sustainability Tracking Assessment Report System (STARS) rating, or lack thereof, has an effect on student environmental literacy (attitudes, knowledge and environmental behaviors). I am conducting a survey of students about their environmental literacy (environmental attitudes, behaviors, and knowledge). Your participation will be extremely appreciated and essential for the completion of my project. I have provided a link to the survey below. Please send the link to your students along with the following brief explanation of the survey. Since I am trying to reach a broad range of students in a variety of majors, please send this link to your colleagues. If you can, please ask them to also have their students participate, for this would increase my sample size, and deliver more accurate data and reach my desired survey count. If you have an interest in the outcome of this project, please let me know, and I will be happy to share my results with you!

Hello! Thank you for your participation. Please click on the link for the survey. The survey should not take more than 5 minutes to complete. You may stop the survey at anytime.

IMPORTANT: You must fill out the name of your university, or else your survey will be invalid. The information you provide is will be kept completely confidential. Completion of this survey implies consent of participation in this research.

If you have questions about the survey, you can contact AnaLisa Campos at (951) 255-7161, or e-mail analisa.campos@sjsu.edu.

[Attached Link to Survey]

Thank you so much, AnaLisa Campos 


\section{Appendix B: Environmental Literacy Survey Instrument}

My name is AnaLisa Campos, and I am a graduate student in the Department of Environmental Science at San Jose State University. As part of my Master's Thesis, I am conducting research on how school's STARS-rating, or lack thereof, has an effect on student environmental literacy (attitudes, knowledge and environmental behaviors. The scores from each university and accompanying data will be available to the public after the completion of this project.

Should you choose to participate, you will be asked to answer questions about your attitude and knowledge about the environment, as well as environmental behaviors. The survey should not take more than 5 minutes to complete.

There is no compensation for participation. The information you provide will be kept completely confidential.

Your participation in this study is completely voluntary. You can refuse to participate in the entire study or any part of the study without any negative effect on your relations with San Jose State University or any university that you currently or previously attend. You also have the right to skip any question you do not wish to answer.

Your participation will, however, help us to better understand the impacts of a school's sustainability efforts on student environmental literacy.

If you have questions about the survey, you may contact AnaLisa Campos at (951) 2557161, or e-mail analisa.campos@sjsu.edu. Your completion of the study indicates your willingness to participate. Please keep this document for your records.

Thank you very much for your help and participation!

AnaLisa Campos

San Jose State University 
IMPORTANT: You must fill out the name of your university, or else your survey will be invalid. Instructions for taking the survey: Please answer the questions truthfully and to the best of your ability. Fill in only ONE answer for each question asked. There are three sections in the survey. Each section is different so please read the directions carefully before starting each section.

Background questions. IMPORTANT: MUST fill out which university you attend.

Which university do you attend?

What is your major?

What is your class?

$\square$ Freshman

$\square$ Sophomore

$\square$ Junior

$\square$ Senior

$\square$ Graduate

$\square$ First year graduate student from the same undergraduate school

$\square$ First year graduate student from different undergraduate school

$\square$ Second or more year graduate student

What is your age?

What is your gender?

$\square$ Female

$\square$ Male

$\square$ Prefer not to answer 
Instructions for Section A: Please indicate how you feel about each statement below. There are no right or wrong answers. Read each statement carefully. Use the following key: Strongly Agree, Agree, No Opinion, Disagree, Strongly Disagree

A1. I think most of the concern about environmental problems has been exaggerated.

$\square$ Strongly Agree

$\square$ Agree

$\square$ No Opinion

$\square$ Disagree

$\square$ Strongly Disagree

A2. I believe that I can contribute to the solution of environmental issues by my actions.

$\square$ Strongly Agree

$\square$ Agree

$\square$ No Opinion

$\square$ Disagree

$\square$ Strongly Disagree

A3. More controls should be placed on industry and agriculture to protect the quality of the environment, even if it means that the things I purchase will cost more.

$\square$ Strongly Agree

$\square$ Agree

$\square$ No Opinion

$\square$ Disagree

$\square$ Strongly Disagree

A4. More land should be set aside for wildlife habitats.

$\square$ Strongly Agree

$\square$ Agree

$\square$ No Opinion

$\square$ Disagree

$\square$ Strongly Disagree

A5. I am not concerned about the rate of species extinction in the world.

$\square$ Strongly Agree

$\square$ Agree

$\square$ No Opinion 
$\square$ Disagree

$\square$ Strongly Disagree

Instruction for Section B: For the following group of statements, please indicate how frequently you do each of the actions mentioned. Be honest, there are no right or wrong answers. Use the following key: almost always, often, sometimes, almost never, never

B1. I turn off lights and appliances when they are not being used to conserve electricity.
$\square$ Almost always
$\square$ Often
$\square$ Sometime
$\square$ Almost never
$\square$ Never

B2. I support candidates for political offices who are concerned about environmental problems and issues.
$\square$ Almost always
$\square$ Often
$\square$ Sometime
$\square$ Almost never
$\square$ Never

B3. I recycle paper, glass and/or metal waste products at home or at school.
$\square$ Almost always
$\square$ Often
$\square$ Sometime
$\square$ Almost never
$\square$ Never

B4. I write or call politicians to express my views about environmental issues.
$\square$ Almost always
$\square$ Often
$\square$ Sometime
$\square$ Almost never
$\square$ Never

B5. I purchase one product over another product because it is packaged in reusable, returnable or recyclable containers or packages. 
$\square$ Almost always

$\square$ Often

$\square$ Sometime

$\square$ Almost never

$\square$ Never

Instructions for Section C: For each of the following questions, choose the best answer.

C1. Based upon major ecological principles, we should conclude that

A. humans are a climax species that will last indefinitely.

B. the human species will soon become extinct; nothing we can do will prevent this.

C. the human species will last as long as there is a balanced ecosystem that will support human life.*

D. there is no way of predicting what will happen to the human species; ecological principles do not apply to humans.

C2: Which of the following contributes to air pollution at the surface of the earth, and acts as a shield against ultraviolet rays in upper atmosphere?
A. Nitrous oxide
B. Methane
C. Ozone*
D. Sulfur dioxide

C3. The main source(s) of emissions that have been identified as contributing to acid deposition (acid rain) in the United States are
A. volcanoes and forest fires
B. petroleum refineries
C. automobiles and coal burning power plants
D. aerosol sprays and refrigerant leakage*

C4. The rate of species' extinction is higher now than at any time since the period of the dinosaurs' extinction. The main cause of this rapid decline in biodiversity is

A. habitat alteration by humans.* 
B. the illegal poaching or collecting of animals and plants.

C. changes in the Earth's atmosphere due to human activities.

D. hunting by humans for food or sport.

C5. Which of the following is most likely to help endangered species?
A. Outlaw the sale or possession of endangered species or products made from them (skins, furs, ivory, etc.)
B. Create breeding programs in zoos for endangered animals.
C. Use farming methods which do not damage habitat.
D. Maintain large protected natural areas where they live.*

This is the end of the survey. Thank you for your participation! 